\title{
NATURALEZA, CONTENIDO Y PRINCIPIOS DEL DERECHO URBANÍSTICO CHILENO*
}

\section{EDUARDO CORDERO QUINZACARA**}

RESUMEN: Esta investigación tiene por objeto determinar la naturaleza del Derecho urbanístico en el ordenamiento jurídico chileno, establecer cuáles serían los contenidos que permiten darle una singularidad respecto de otras disciplinas y, especialmente, determinar si es posible sostener que en nuestro país constituye una rama autónoma del derecho y cuáles serían los principios e instituciones que lo conforman.

PALABRAS CLAVE: Derecho urbanístico - principios - instituciones

\section{Nature, Content and Principles of The LaW of URBANISM IN CHILE}

ABSTRACT: This research aims to determine the nature of planning law in the Chilean legal system. In order to do so, this paper discusses about the identity of its contents, its autonomy as a legal discipline, and its framework of principles.

KEYWORDS: Law of Urbanism - principles - institutions

\section{INTRODUCCIÓN}

Toda disciplina dogmática tiene por objeto conocer y explicar sistemáticamente el contenido de un sector del derecho positivo, a través de un método que permita acometer la labor mediante la interpretación de sus normas, para reducirlas posteriormente a principios e instituciones que finalmente van a integrar un sistema. A partir de dicho momento es

Este trabajo es parte de una investigación financiada por FONDECYT referida al proyecto "La revisión de las bases dogmáticas del Derecho urbanístico chileno. Propiedad, urbanismo y regulación de las actividades económicas" № 1130956.

Fecha de recepción: 12 de marzo de 2014.

Fecha de aceptación: 12 de marzo de 2015.

** Abogado, Doctor en Derecho, Profesor de Derecho administrativo de la Pontificia Universidad Católica de Valparaíso (CHILE). Correo electrónico: eduardo.cordero@ucv.cl. 
posible sostener que estamos ante una disciplina jurídica o rama del derecho, compuesta por un conjunto de normas, principios e instituciones que permiten distinguirla respecto de otras ramas o disciplinas. De esta forma han ido adquiriendo estatus científico las disciplinas más tradicionales del Derecho, como sucede con el Derecho civil, comercial, procesal, constitucional, administrativo y constitucional. Al mismo tiempo, la evolución social y económica ha ido abriendo espacio a nuevas regulaciones $y$, a su vez, a nuevas ramas autónomas, que se han ido desgajando de las tradicionales, como ha sucedido con el Derecho del trabajo o el Derecho de familia.

En dicho contexto, a partir de la segunda mitad del siglo XIX hemos asistido a un cambio en la estructura social producto de la industrialización, que ha dado lugar a un proceso de migración de la población desde el campo hacia las urbes, generando una enorme presión en las vetustas ciudades medievales y coloniales, trayendo aparejado una serie de problemas de higiene, salubridad y seguridad, que se ha ido enfrentando con las precarias herramientas que ha entregado la legislación liberal de la época, particularmente el Derecho municipal y las ordenanzas locales. Dada la urgencia, el problema se ha debido asumir mediante la dictación de un conjunto de textos legales que han tenido por objeto emprender la reforma interior de las viejas ciudades y el ensanchamiento de las poblaciones mediante nuevas técnicas de intervención desconocidas para la época.

Desde aquellas leyes urbanísticas hasta la actualidad, hemos asistido a la existencia de un corpus normativo mucho más complejo y que se comprende bajo la denominación de Derecho urbanístico, cuyas disposiciones han ido conformando un conjunto de normas, principios e instituciones que reclaman un tratamiento separado y sistemático, conformando lo que para algunos sería una disciplina autónoma.

En tal sentido, el objeto de este trabajo es determinar cuál es la naturaleza de esta rama del Derecho en nuestro ordenamiento, cuáles serían los contenidos que permiten darle una singularidad respecto de otras disciplinas y, especialmente, determinar si es posible sostener que en nuestro país el Derecho urbanístico constituye una rama autónoma del derecho y cuáles son los principios e instituciones que conforman dicha disciplina.

\section{1) UNA DISTINCIÓN PREVIA: EL URBANISMO COMO HECHO HISTÓRICO, EL URBANISMO COMO DISCIPLINA CIENTÍFICA Y EL DERECHO URBANÍSTICO}

Antes de analizar la naturaleza y contenido del Derecho urbanístico nacional, resulta necesario hacer una distinción previa entre lo que es el urbanismo como fenómeno o hecho histórico y disciplina científica, frente 
al urbanismo en su dimensión normativa o lo que se ha denominado $D e$ recho urbanistico, que no es sino la dimensión jurídico-administrativa del urbanismo.

El "Urbanismo como hecho histórico" se expresa desde antiguo en las distintas sociedades mediante la formación y crecimiento de las ciudades, los trazados y medios de comunicación que atraviesan el territorio, así como la transformación del territorio rural para fines urbanos. Así es posible encontrar distintas tradiciones y formas urbanísticas, que van desde la ciudad antigua, pasando por la ciudad medieval y la ciudad barroca, hasta llegar al fenómeno de las concentraciones masivas a partir del siglo XIX. Estos constituyen espacios cuya configuración deriva de las tensiones de subsistencia del hombre como especie y de los conflictos culturales y estratégicos de dominación de los grupos sociales sobre el medio físico territorial y sobre otros grupos o culturas antagónicas, y que se concretan en los asentamientos, ciudades y vías que delimitan espacios territoriales adaptados a dichos grupos culturales y que son, recíprocamente, condicionados por su ámbito físico ${ }^{1}$.

Por su parte, el "Urbanismo como disciplina técnico-científica", más o menos consciente de todos los elementos y relaciones que contempla y con la complejidad teórica con que hoy se concibe, solo inicia su desarrollo en la segunda mitad del siglo XIX, cuando se comienza a teorizar -como bien dice Tomás-Ramón Fernández- sobre los espacios urbanos desde una perspectiva global e integradora respecto de todo lo que se refiere a la relación del hombre con el medio en que se desenvuelve y que hace de la tierra, del suelo, su eje operativo ${ }^{2}$.

1 García-Bellido, Javier (1994). "Inicios del lenguaje de la disciplina urbanística en Europa y difusión internacional de la "Urbanización" de Cerda", en Tiempo y Espacio en el Arte. Homenaje al profesor Antonio Bonet Correa, Tomo II, Madrid, Universidad Complutense de Madrid, p. 267.

2 Fernández, Tomás-Ramón (1997) Manual de Derecho Urbanistico. 12a ed. Madrid: El Consultor, p. 18. Esto fue lo que sucedió durante la segunda mitad del siglo XIX con la novel disciplina del urbanismo. Este proceso semiológico está marcado por el aporte de Idelfonso Cerdá (1819-1876), quien acuña el concepto o voz significante de "Urbanización”, utilizada en el año 1867 al publicar el primer tratado teórico-práctico de la nueva ciencia que él denomina "urbanización" o "ciencia urbanizadora" con el título “Teoría General de la Urbanización”. En esta obra CERDÁ desarrolla ampliamente las múltiples acepciones de esta voz, explicando su etimología, la que terminará asentándose en el lenguaje técnico durante el siglo XIX y principios del siglo XX. Sin embargo, en los ańos veinte, esta voz sería reservada para los contenidos más técnicos y proyectuales, tomándose del francés la voz urbanismo para los contenidos teóricos y disciplinares más amplios, en concurrencia de la voz Urbanistica. Véase García-Bellido (1994) p. 1109. En Alemania las primeras denominaciones vienen de la mano de Reinhard Baumeister (1833-1917), quien utiliza la voz Stadt-Erweiterungen (1876), que puede traducirse como ensanche de ciudades. Al parecer con esta expresión se quería significar la disciplina misma, la técnica y arte que abordaba los problemas de la "urbanización", en abstracto, aunque inicialmente referida a los "ensanches" de poblaciones. Posteriormente Camilo SitTe (1843-1903) acuñaría el actual lexema Städtebau (1889). En Francia se acuña el término urbanisme por Pierre 
Por último, el Derecho urbanístico tiene distintas connotaciones y alcances, según cada momento histórico. En sentido amplio, por Derecho urbanístico podemos comprender todas las disposiciones de incidencia urbanistica dictadas durante la historia y que han tenido cierta persistencia en la legislación actual, frente a las normas urbanísticas propiamente tales o de Derecho urbanístico stricto sensu, que responden al fenómeno que se produce en la segunda mitad del siglo XIX y que da lugar a la existencia de una función pública específica, con instituciones propias, que busca obtener un orden racional del espacio y la ciudad. Así, este concepto se encuentra vinculado a las últimas fases o etapas del fenómeno urbano, cuya causa eficiente es la revolución industrial, que marca el momento en que occidente comienza a dejar de ser una civilización agraria, debido a la industrialización y a los progresos que se experimentan en la explotación agrícola y ganadera, y se concentra un porcentaje creciente y mayoritario de la población en las ciudades, creando aglomeraciones caóticas, barrios marginales y miserables ${ }^{3}$. Sobre esta nueva realidad histórica se desarrollan las bases de una legislación urbanística que tiene por objeto la ordenación de la ciudad, la creación de nuevos espacios y la protección de la población a través de un conjunto de medidas sanitarias y de habitabilidad.

\section{2) DERECHO URBANÍSTICO Y DERECHO PRIVADO: LA CONCEPCIÓN LIBERAL DE LA PROPIEDAD}

En su origen el Derecho urbanístico aparece vinculado con el Derecho privado, particularmente al Derecho civil, a partir de la respuesta que entregaban los juristas sobre la base de los conceptos jurídicos liberales que proclamaban el carácter absoluto del derecho de propiedad, ante la existencia de limitaciones a la misma en virtud de diversos títulos (orden público, salubridad, urbanismo, etc.). En este caso se entiende que la propiedad del suelo, tanto urbana como rural, es un tipo de propiedad civil al cual le resultan aplicables las normas matrices contenidas en el Código Civil, sujeto a las limitaciones que emanan de una legislación que se considera excepcional.

Clerget en 1910, la que tendría una enorme difusión en todas las lenguas, en cuanto concepto técnico que comprendería a esta nueva disciplina, y que penetrará en Espańa como urbanismo hacía 1920, desplazando el lexema urbanización de CERDÁ. Por su parte, en Italia ya se utilizaba esta expresión en el año 1902.

3 Al respecto García de Enterría, Eduardo y Parejo Alfonso, Luciano (1981) Lecciones de Derecho urbanístico. 2 ed. Madrid: Civitas, p. 43, dan algunas cifras: A lo largo del siglo XIX Europa pasó de 180 millones de habitantes a 400; Estados Unidos, de 5 a 74; Hispanoamérica, de 20 a 50. Por su parte, ciudades como Londres pasa de 500.000 a 2.700.000, Nueva York, de 60.000 a 3.500.000, etc. 
En este primer período la inserción y comprensión de la legislación urbanística dentro del sistema de derecho privado se hace a través de una técnica muy simple: se concibe la propiedad como un derecho lo más amplio y absoluto posible -cuyo sentido original está en la naturaleza humana, que es su fuente- y dejar a posteriori su configuración al legislador, quien le dará la forma que garantice el ejercicio de todos los derechos de propiedad, sin que alguno impida el ejercicio de otros. Por tal razón no es posible definir el derecho de propiedad sino que en su forma original, la que no se identifica con lo que en la realidad existe ${ }^{4}$. Además, acorde con la concepción liberal, las limitaciones son entendidas como deberes negativos de "no hacer" establecidos en razón del interés privado, es decir, se ocupan de resolver los conflictos interindividuales, desentendiéndose del interés social de la comunidad 5 .

Sin embargo, producto de los cambios sociales experimentados en las últimas décadas del siglo XIX, el régimen del derecho de propiedad no se limitará a resolver los conflictos de intereses que puedan surgir entre propietarios. Ahora el conflicto de intereses es de mayor entidad, ya que este se plantea entre el interés particular del propietario y el interés social de la colectividad. Por su parte, la función del legislador también cambia, porque este ya no se restringe a una acción de limitación posterior y como mero árbitro entre los conflictos de los particulares, sino que debe configurar el régimen el derecho de propiedad por razones de interés general o público, dándole un sentido funcional dentro del ordenamiento jurídico. Además, las leyes especiales que fueron concebidas como excepciones y fragmentaciones del sistema codificado unitario, se transforman en normas habituales y permanentes producto de las grandes crisis derivadas de la Primera Guerra Mundial y las revoluciones coetáneas. De esta manera, las leyes especiales contribuyen a crear una nueva dimensión o statu quo social del Derecho en un camino o dirección que no dejaba posibilidad alguna de retorno. Como afirma López y López: "El Código, en muchos aspectos, pertenecía a un mundo periclitado, y nada abonaba su permanencia como regla general operativa que impidiera la entrada en el mundo del Derecho "normal" de las otrora Leyes "especiales" (en el sentido de "excepcionales"), y por consiguiente su inasequibilidad a la analogía y

4 Con posterioridad en Alemania Antón Menger (1841-1906) dará cuenta de esta situación diciendo: "La verdad es que estas restricciones de la propiedad privada encuentran expresión únicamente en manuales, y al margen de los compendios de Derecho civil [...] pero ¿no sería ya hora de derribar de una vez por todas esa débil pared e incluir en las definiciones del Código civil la lamentable situación del propietario actual?". Véase Hattenhauer, Hans (1987) Conceptos fundamentales del Derecho civil. Introducción histórico-dogmática. Traducción de Gonzalo Hernández. Barcelona: Ariel, p. 121.

5 Véase Colina Garea, Rafael (1997) La función social de la propiedad privada en la Constitución Española de 1978. Zaragoza: Bosch, 1997, pp. 94-97. 
su anclaje en la interpretación restrictiva, como principio hermenéutico propio" 6 .

Los excesos del individualismo y la crítica desde el plano de la ética o la moral se tradujeron en el plano jurídico en un conjunto de cuestionamientos y en una revisión de la tradicional categoría de la propiedad liberal, con el objeto de orientar el poder del propietario al interés de toda la colectividad y no servir únicamente a su interés individual. Un buen ejemplo de este cambio se puede ver en la obra de Gabriel BAUDRYLacantinerie, quien expresaba en las primeras ediciones de su Précis de droit civil que el propietario "[...] puede legítimamente realizar sobre la cosa actos aunque no tenga ningún interés confesable en realizarlos [...]" y si, al realizarlos causa un daño a otro "[...] no es responsable, porque no hace más que usar su derecho"7. Sin embargo, esta fórmula desaparece a partir de la $11^{\circ}$ edición de 1912 , y en su lugar queda la declaración que ya venía formulando con la colaboración de Chauvea en su obra Des Biens: "A pesar de su carácter absoluto, la propiedad debe también estar circunscrita a límites racionales [...] El mismo artículo 544 se ocupa de anunciar la existencia de restricciones a las cuales el derecho de propiedad es susceptible de estar sometido. Intereses de orden superior, de orden social, de orden general o público, imponen a veces que se doblegue un poco el absolutismo del derecho de propiedad, que se prohíba a los propietarios ciertos actos de ejercicio, incluso que se les obligue a hacer alguna cosa, a cumplir diversas obligaciones, por el solo hecho de ser detentadores de bienes colocados bajo ciertas condiciones. El legislador, bajo la única reserva del respeto a la constitución y a los principios del derecho público, es libre de determinar la extensión del sacrificio que la propiedad debe sufrir en interés general'8.

López y López Ángel (1998). "El derecho de propiedad. Una relectio". Anuario de Derecho Civil, T. LI, fasc. IV, octubre-diciembre, p. 1642.

7 La primera edición es de 1882-1884 [Baudry-Lacantinerie, Gabriel (1882-1884) Précis de Droit civil. 3 vol. Paris: Larose. La cita la hemos tomado de la $10^{\text {a }}$ ed. [BAUdrYLacantinerie, Gabriel (1908) Précis de Droit civil. vol. 1, 10a ed. Paris: Larose, No 1296, p. 726]

8 Baudry-Lacantinerie, Gabriel y Cheveau, M. (1905) Traité théorique et pratique de droit civil: Des Biens. $3^{a}$ ed. Paris: Recueil Sirey, pp. 150-160. El destacado es nuestro. Por su parte De VITA, Anna (1969) La propietà nell'esperienza giuridica contemporánea: analisi comparativa del diritto francese. Milano: Giuffrè, pp. 49-50, señala que las transformaciones que el sentido de la norma del Code civil sufre en el Derecho francés pueden reducirse a los siguientes factores: a) el creciente número de límites que de hecho o de derecho han restringido notablemente el ámbito de ejercicio de las prerrogativas del propietario; b) los efectos de la doctrina del relativismo jurídico, y de la ideología antiindividualista en el plano conceptual, c) a la obra de la jurisprudencia en la construcción del principio del abuso del derecho, que se inserta en la amplia problemática de los límites y de la función social de la propiedad, y a la protección siempre mayor concedida a derechos e intereses del arrendatario y, en particular, del arrendatario comerciante. 
No obstante, esta propuesta se mantiene bajo la estela metodológica liberal, pues a pesar de la intensidad de estas "restricciones" o "sacrificios", se siguen comprendiendo estas medidas en la idea de limitaciones al poder del propietario que no encuentran su raíz en dicho poder, sino aliunde, es decir, externamente, como sucede con la soberanía política. En sí mismas, tales limitaciones son ajenas a la potestad del sujeto propietario, y vienen residenciadas en la necesidad de considerar jurídicamente existentes a los otros, sean los otros propietarios, sea el otro soberano actuante sobre las cosas, el Estado, en función de prerrogativas que le son propias.

A pesar de lo anterior, algunos autores van a persistir en esta posición, aun cuando las limitaciones que se imponen a la propiedad del suelo son de una magnitud y una profundidad que prácticamente rompen con los presupuestos de la propiedad liberal contenida en los Códigos Civiles y, especialmente, con los niveles de decisión que se le asignan al titular del derecho. Así, por ejemplo, en los albores de la nueva legislación urbanística española algunos autores insistían en analizar la legislación urbanística desde la perspectiva del derecho privado en la cual subyace la propiedad privada de tipo quiritario ${ }^{9}$, entendiendo que los deberes sociales eran solo limitaciones al libre ejercicio de las facultades dominicales ${ }^{10}$. Sin embargo, este modelo de comprensión de la propiedad del suelo sería superado al poco tiempo por la legislación, la doctrina y la jurisprudencia, entendiendo que la ordenación urbanística determina el "contenido" del derecho de propiedad, mediante la fijación tanto de los límites dentro de los cuales pueden ser ejercidas las facultades como de los deberes que han de ser cumplidos ${ }^{11}$.

Ahora bien, no obstante lo anterior, esta forma comprender la relación entre Derecho urbanístico y Derecho privado todavía se mantiene implícita en nuestra doctrina y jurisprudencia nacional. En efecto, en lo

9 Véase: De Los Mozos, José Luis (1961). "El urbanismo desde la perspectiva del Derecho privado”. Revista de Derecho Privado, XLV, enero-diciembre. Este autor señala que junto a la propiedad privada de tipo quiritario, no afectada absolutamente por función social alguna, o en muy pequeña medida, se alinean en el Derecho moderno la propiedad privada de idéntico significado sometida a numerosas limitaciones que determinan su normal contenido, impuestas en atención a una función social genérica y circunstanciada en cada caso, a la vez, lo que ya ha sido previsto en la codificación (artículo 348 del Código Civil); y junto a ella nuevas formas de propiedad privada (agraria, urbanística, de la vivienda, etc.) respondiendo a los principios programáticos y constitucionales (Fuero del Trabajo, Fuero de los Españoles, Ley de Principios Fundamentales del Movimiento y del Estado) de un orden social y político nuevo y conforme a la configuración establecida en sus ordenamientos respectivos. Por tal razón, afirma que en el segundo de los supuestos contemplados, la función social, entendida en el sentido indicado, determina limitaciones; en el tercero, ocurre algo más profundo, la propiedad misma se transforma.

10 Núñez Ruiz, Miguel Angel (1967) Derecho urbanistico español. Madrid: Montecorvo, p. 182.

11 Véase Parejo Alfonso, Luciano (1986) Derecho urbanístico. Instituciones Básicas. Buenos Aires, Ediciones Ciudad Argentina, p. 88. 
que dice relación con el régimen jurídico de la propiedad inmobiliaria, en su jurisprudencia general tanto el Tribunal Constitucional ${ }^{12}$ como la Corte Suprema ${ }^{13}$ han utilizado como elemento de referencia el concepto civil de propiedad. Frente a este concepto unitario de propiedad, la jurisprudencia ha entendido que toda acción pública -dentro de la cual podemos comprender a las acciones derivadas de la función pública del urbanismo- puede intervenir imponiendo limitaciones o privaciones al dominio. Según el TC "es fundamental distinguir entre la privación y las limitaciones al dominio, pues el sustento de la privación es el interés nacional y la utilidad pública, en cambio el fundamento de las limitaciones al dominio lo constituye la función social que debe cumplir la propiedad. Además, privación supone, según su sentido natural y obvio "despojar a uno de una cosa que poseía" (Diccionario de la Lengua Española, 1992, Tomo II, pág. 1969). En igual sentido se ha fallado que privar a alguien de un derecho consiste en "apartar a uno de algo o despojarlo de una cosa que poseía” (Corte Suprema, 27.03.1983, Rev. 80, sección 5aa, pág. 244). Limitar, en cambio importa "acortar, cerrar, restringir" (Diccionario de la Lengua Española, 1992, Tomo II, pág. 1258). De esta manera las limitaciones suponen el establecimiento de determinadas cargas al ejercicio de un derecho, dejándolo subsistente en sus facultades esenciales" ${ }^{14}$. Siguiendo esta misma línea argumental, el Derecho urbanístico constituiría una limitación a las facultades absolutas del propietario, de acuerdo con la definición que da el artículo 582 del Código Civil. Así, por lo demás, lo ha entendido la Contraloría General de la República, que ha sostenido que la LGUC ha establecido normas sobre la planificación intercomunal y comunal y de su aplicación resultan limitaciones -impuestas por la leyal dominio, cuyo fundamento está en la función social de la propiedad ${ }^{15}$. En tal sentido, "el artículo 582, del Código Civil, al definir el dominio, reconoce que las facultades que confiere el derecho de propiedad pueden limitarse por ley. Las limitaciones establecidas por la ley civil derivan de la función social del dominio. Tratándose de la normativa urbanística, el pretendido carácter absoluto del dominio puede verse constreñido por ella, que pasa a constituir un límite de las facultades o atributos esenciales de la propiedad, en interés de la sociedad y en resguardo del bien común"16.

\footnotetext{
12 Tribunal Constitucional, 16 de julio de 1982, Rol No 12, y de 1 de septiembre de 1987, Rol No 47.

13 Corte Suprema, 8 de junio de 1990, Rol No 14.444. Gaceta Jurídica N²120, junio, 1990, p. 28; y de 10 de abril de 1992, Rol No 16.672. Gaceta Jurídica $N^{\circ} 142$, abril, 1992, p. 28.

14 STC Rol No 245, de 2 de diciembre de 1996, considerando 22..

15 Dictamen No 10.254 , de 2006.

16 Dictamen No 7805, de 1997.
} 
También la doctrina mantiene una posición similar, en donde la pieza fundamental sigue siendo el concepto abstracto, unitario y absoluto de la propiedad, tal como la define el artículo 582 del Código Civil, de forma que el Derecho urbanístico se presenta como un sistema de limitaciones a la propiedad, todas las cuales caen bajo el concepto clásico de policía municipal. Así, autores como Enrique Brahm García, quien comentando la normativa sobre urbanización dictada en Chile desde mediados del siglo XIX, sostiene que "el detalle de limitaciones y de directas privaciones del dominio no podía ser más agobiante. La propiedad inmueble urbana pasaba a ser, por excelencia, una forma de propiedad limitada. Surge así el Derecho urbanístico"17. Por su parte, Enrique RAJEVIC afirma en breves palabras que "usualmente las normas urbanísticas impondrán limitaciones al derecho de propiedad privada"18. Desde una perspectiva similar, algunos autores tienden a asimilar la propiedad civil con la propiedad regulada a nivel constitucional, tal como en su momento lo hizo nuestra Corte Suprema, para sostener un concepto unitario de este derecho anclado en su contenido esencial e insertar las normas urbanísticas como formas de limitación a la propiedad derivada de su función social ${ }^{19}$. En todo caso, este cambio de perspectiva busca residenciar los problemas de la propiedad desde el ámbito civil al constitucional y solo demuestra la escisión del Derecho urbanístico con respecto al Derecho privado, colocando el tema de las limitaciones como una cuestión propia de la dogmática constitucional de la propiedad.

\section{3) Derecho urbanístico y Derecho público: la función PÚBLICA DEL URBANISMO}

La proliferación de la legislación social extra Código y su constitucionalización provocaron un cambio importante en la metodología e interpretación del Derecho urbanístico, lo que se notó especialmente en la distinción que se hacía entre Derecho normal y excepcional ${ }^{20}$. Si bien

17 Brahm García, Enrique (1999) Propiedad sin Libertad. Chile 1925-1973. Santiago: Universidad de los Andes, p. 75.

18 Rajevic Mosler, Enrique (2001). "La planificación urbana en Chile". Revista de Derecho, Consejo de Defensa del Estado, Año 1, No 3, abril, p. 532

19 Véase Fernández Richard, José y Holmes Salvo, Felipe (2008) Derecho Urbanístico Chileno. Santiago: Editorial Jurídica de Chile, p. 29, en la cual sostienen que: "En conclusión, el Derecho Urbanístico contiene limitaciones al dominio en razón de la función social del mismo, específicamente por causa de utilidad pública, ya que significa un beneficio colectivo, referido especialmente al orden interior de la República”. En el mismo sentido, Holmes Salvo, Felipe (2010) Propiedad Urbana. Régimen Jurídico. Santiago: AbeledoPerrot, pp. 73 y ss.

20 Las normas que regulaban las nuevas circunstancias sociales, económicas y políticas surgidas después del procesos de industrialización van a colocar límites sustanciales a la autonomía 
estas normas fueron interpretadas de forma restrictiva al constituir un Derecho excepcional respecto de la libertad y de autonomía privada, posteriormente hubo un cambio de perspectiva a la luz de las cláusulas económicas y sociales contenidas en las Constituciones de comienzo del siglo $\mathrm{XX}$, que transforman estas limitaciones en un Derecho normal ${ }^{21}$.

Se trata de un conjunto importante de normas que lejos de ser excepcionales, se mantendrán en el tiempo y responderán a un sistema o ethos interno que buscará dar racionalidad y orden al uso del espacio y a las actividades que en él se desarrollan. Ya no estaremos solo frente a una legislación singular y concreta, como sucedió con nuestras primeras leyes urbanísticas de fines del siglo XIX y principios del XX, dictadas para determinadas ciudades (Santiago, Valparaíso, Curicó, Talca, Valdivia y Concepción), sino que se establecerá un cuerpo integrado de normas, primero como parte del Derecho municipal (1915) y luego como textos independientes y sistemáticos (1929). Así, la legislación urbanística comenzará a ser objeto de estudio y análisis dogmático a partir de un conjunto de principios y por la incorporación de nuevas instituciones jurídicas. Las nuevas prerrogativas de la autoridad en estas materias no serán producto de la contingencia o la coyuntura, sino que marcarán el inicio de un conjunto de técnicas de intervención que se institucionalizarán a partir de la planificación urbana, el control preventivo en las edificaciones, la ejecución del planeamiento y los mecanismos de fiscalización y sanción. Así, la novel regulación será objeto de reflexión científica y se analizará siguiendo los patrones de la dogmática jurídica, dando origen al Derecho urbanístico.

privada de la voluntad, lo que difiere con el principio general de libertad consagrado en las Constituciones y Códigos del siglo XIX. Como estas normas implican un alejamiento o restricción de estos principios fueron calificadas como excepcionales, lo que traía aparejada una consecuencia importante: la interdicción de su aplicación analógica. Como decía Federico de Castro, estas normas iban contra tenorem rationem [Derecho civil en España. Madrid, 1984, p. 172]. Aunque esta regla no estaba consagrada expresamente en el Code civil francés, la falta de efecto expansivo de las normas excepcionales se deducía del propio efecto expansivo de los principios generales. Las limitaciones a estos principios solo eran excepciones y por razones de utilitas. La proliferación de leyes especiales llevó a la consagración expresa de esta disposición, como ocurrió en el artículo 4 de las Disposiciones Preliminares del Código civil italiano [Las leyes penales y aquellas que restringen el libre ejercicio de los derechos o forman excepción a las reglas generales o a otras leyes, no se extienden más allá de los casos y en los tiempos que en ellas se expresan]. El Código Civil español de 1889 no contempló en su texto original esta regla hasta la reforma del Título Preliminar de 1974 (artículo 4.2.).

21 Cordero (2008b), 104. La propiedad ya no es considerada un derecho absoluto y libre, y pasa a estar determinada funcionalmente. Así lo consagra la Constitución de Weimar en su artículo 153 [Eigentum verpflichtet. Sein Gebrauch soll zugleich dem Wohle der Allgemeinheit dienen]. De esta manera, la función social de la propiedad es reconocida como un principio general y de contenido normal de dicho derecho, con lo que se integra dentro del ámbito jurídico normal, lo que le permite adquirir una verdadera vis expansiva, pudiendo ser aplicada por la vía analógica, cuestión que jamás previeron los redactores y comentaristas del Código Civil. 
En este contexto, el Derecho urbanístico se constituye como un sistema cuyo objeto son aquellos principios y normas que regulan la actividad de la autoridad pública y de los particulares en la búsqueda de un orden racional en los usos y actividades que se desarrollan en el suelo urbano y rural. De esta forma, se produce la separación de esta disciplina del Derecho privado, particularmente del Derecho civil. Ya no estamos frente a limitaciones externas de la propiedad civil que vienen desde una legislación excepcional, sino que ante disposiciones que configuran un distinto tipo de propiedad a partir de su función social.

Ahora bien, en sus inicios el Derecho urbanístico surge como parte de la actividad de policía, más concretamente de la policía urbana, en donde las técnicas de intervención (alineamientos, la zonificación, la planificación, expropiación), eran consideradas limitaciones externas al derecho de propiedad. El cambio evolutivo hasta el Derecho urbanístico actual, como mecanismo que interviene y configura el contenido material del derecho de propiedad sobre el suelo se ha debido no solo a una reacción frente a los nuevos desafíos sociales que ha debido enfrentar el Estado, sino también a un cambio en la concepción jurídico-dogmática de este derecho, así como de las concepciones filosóficas, económicas y políticas que se han construido en torno a él a partir de la época de la ilustración.

Es en este momento que se enfrentan dos concepciones para comprender el régimen de la propiedad del suelo. La primera se sitúa en la esfera del titular del derecho de goce y disposición para, desde la misma, afirmar el principio de libertad dominical de uso y provecho con las solas limitaciones (externas) que el interés le imponga. Por su parte, la segunda se coloca, por el contrario, justamente en el lugar de los intereses colectivos o comunitarios para, sin desconocer los del titular del derecho, sostener la primacía de los mismos y reducir la libertad del propietario al espacio residual resultante (conforme, en todo caso, al interés general) ${ }^{22}$. La primera de estas concepciones se formula dentro de los esquemas y conceptos jurídicos del Estado liberal burgués, que determina, a su vez, los esquemas y conceptos del Estado de Derecho. La segunda es fruto del Estado social, que expresa la profunda transformación en la concepción del derecho de propiedad a consecuencia de las nuevas características económicas de la sociedad industrial, imponiendo un nuevo fin legitimador de este derecho (la función social) que opera desde su interior (y no sobre él o desde fuera del mismo), conformando su propio contenido.

22 Parejo Alfonso, Luciano (2001). "Algunas consideraciones sobre el derecho de propiedad a la luz de la jurisprudencia constitucional”. En López Guerra, Luis (coord.): Estudios de Derecho Constitucional. Homenaje al Profesor Dr. D. Joaquin García Morillo. Valencia: Tirant lo Blanch, pp. 75-118, p. 76. 
El Derecho urbanístico se entronca en esta segunda perspectiva, en donde el Estado debe asumir un función protagónica en la conformación de una sociedad que no tiene la capacidad de resolver por sí misma y de manera espontánea los problemas que se van a gestar en su desarrollo y crecimiento. Así, los elementos que le dan identidad y fisonomía respecto de otras ramas del derecho se fundan en la existencia de principios e instituciones que la asienta en el ámbito del Derecho público y lo separan de las bases, principios y sistemas propios del Estado liberal expresado en los Códigos Civiles y en un modelo de propiedad totalmente superado.

Ahora bien, siendo el Derecho urbanístico una disciplina propia del Derecho público, tanto en lo que dice relación con los principios que la integran, la forma en que se regulan a los sujetos que intervienen en él, las técnicas de intervención, así como en los procedimientos y mecanismos de control, cabe preguntarse si forma parte de una disciplina mayor dentro de esta división del Derecho, como es el Derecho administrativo, o es posible sostener su autonomía.

Si bien en el Derecho comparado se han formulado varias teorías acerca de su naturaleza, la tendencia ha sido la de considerarlo como una disciplina jurídica integrada en el Derecho administrativo ${ }^{23}$, sin perjuicio de que se discuta su autonomía científica ${ }^{24}$. No obstante, algunos autores adoptan una posición matizada a este respecto, afirmando que el contenido de esta disciplina no es solo una corroboración de las categorías dogmáticas ofrecidas por la parte general del Derecho Administrativo, sino un ámbito específico, dominado cada uno por principios propios ${ }^{25}$.

23 Ver entre otros García de Enterría y Parejo Alfonso (1981) 65; Parada, José Ramón (1993) Derecho Administrativo. vol. III, 5a ed. Madrid: Marcial Pons, p. 312, aunque en la $8^{a}$ edición ya no sostiene expresamente esta opinión; y Carceller Fernández, Antonio (1989) Instituciones de Derecho urbanístico. Madrid: Montecorvo, 1989, p. 25.

24 En esta línea Martín Blanco, José (1960) Estudios de Derecho Urbanístico. Madrid: Gráficas Expres, y (1970) Dictámenes y estudios en Derecho urbanístico. Madrid: Montecorvo, ha sostenido que el Derecho urbanístico es un Derecho especial que, participando de normas de Derecho privado y de Derecho administrativo, ofrece cierta peculiaridad que le separa de estos, aunque no está consolidado. En contra de esta tesis se pronuncian autores como Marcos Jiménez, Martín (1976) Parcelaciones y reparcelaciones urbanisticas y el registro de la propiedad. Madrid: Montecorvo; Jardí CasanY, Enrique (1966) El planeamiento urbanistico. Barcelona: Bosch; Martín Gamero, Alberto (1967) Expropiaciones urbanisticas. Madrid: Montecorvo, y, especialmente, GonzÁlez PÉrez, Jesús (1998) Comentarios a la ley sobre régimen del suelo y valoraciones. Ley 6/1998, de 13 de abril. Madrid: Civitas, p. 56, quien sostiene que "el llamado Derecho urbanístico no es una disciplina jurídica autónoma, sino un conjunto de normas jurídicas de naturaleza distinta, informadas por principios harto diferentes. Lo único que existe común entre estas normas es el objeto social regulado por ellas".

25 García de Enterría y Parejo Alfonso (1981) 66, en donde sostienen que estos principios vienen impuestos por “[...] el tratamiento de los problemas urbanos, lo que obliga por ello a conocer al menos en su grandes líneas, las directrices político-urbanísticas en general y su ámbito de cuestiones propias [...]”, de manera tal que “[...] ponen a prueba, 
En Chile no se ha planteado una discusión acabada en torno a la naturaleza del Derecho urbanístico. La mayoría de los trabajos en esta materia se han limitado en muchos casos a exponer el debate que se ha producido en el Derecho español, el que no ha sido, por lo demás, de una gran intensidad ${ }^{26}$.

En todo caso, Fernando Fueyo Laneri ya reconocía la autonomía científica de esta disciplina en la década del 60 del siglo pasado, al sostener que el Derecho urbanístico era una "rama jurídica interdisciplinaria y social, en la que concurren circunstancias que la caracterizan como autónoma (método y sistematización científica propias, autonomía legislativa -ordenamiento propio y orgánico, muchas veces un código- y autonomía didáctica como asignatura separada e independiente)" 27.

José Fernández Richard y Felipe Holmes definen el Derecho urbanístico en términos generales como "la rama del Derecho que estudia el conjunto de principios y normas que regulan tanto la planificación de las ciudades, como el diseño de sus construcciones". En su opinión, el Derecho urbanístico forma parte del Derecho público, sin embargo también hace algunos matices al señalar que tiene aristas que involucran al Derecho privado en las relaciones ulteriores que se producen entre particulares ${ }^{28}$.

Patricio Figueroa Velasco y Juan Eduardo Figueroa Valdés siguen los conceptos que sobre la materia se han vertido en el Derecho espańol, particularmente de José Ramón Parada ${ }^{29}$ y Antonio Cardeller Fernán$\mathrm{DE}^{30}$, afirmando que la naturaleza de función pública que corresponde al urbanismo en Chile no es discutida ${ }^{31}$.

Por su parte, Lautaro Ríos Álvarez, quien a la sazón ha escrito uno de los estudios más completos y acabados sobre la materia en nuestra doctrina, ha afirmado que "parece [...] que el Derecho urbanístico

matizan y en ocasiones rectifican o revisan esas supuestas categorías generales, que son aquí puramente instrumentales para interpretar y comprender un régimen jurídico sustantivo y no secundario o derivado".

26 Ver Álvarez Cruz, Raúl (1988) "La disciplina urbanística. Su entidad ante el Derecho”. Revista de Ciencias Sociales Derecho y Sociedad, No 2, primavera, 1988, pp. 38-40; RajEvic (2001) 530-531, y Guillmore L., Roberto y Guerrero P., Pablo (2001). "Principios del Derecho urbanístico como fuente normativa del desarrollo urbano y las zonas de desarrollo condicionado como instrumento de urbanismo moderno". En Facultad de Derecho de la Universidad del Desarrollo. Derecho urbanístico. Santiago: Universidad del Desarrollo, pp. 13-14.

27 Fueyo Laneri, Fernando (1967) “El problema de las autonomías o especialidades”. Revista de Derecho Privado, No 17, pp. 17-21.

28 Fernández Richard y Holmes (2008) 17-18.

29 Parada, José Ramón (1999) Derecho urbanístico. Madrid, Marcial Pons, p. 2.

30 Cardeller Fernández, Antonio (1992) Introducción al Derecho urbanístico. Madrid, Tecnos, p. 17.

31 Figueroa Velasco, Patricio y Figueroa Valdés, Juan Eduardo (2006) Urbanismo y Construcción. Santiago, LexisNexis, pp. 5-7. 
hubiera venido adquiriendo suficiente organización; un alto grado de elaboración sistemática en lo doctrinal, legislativo y jurisprudencial; atención académica, y la conciencia colectiva necesaria para merecer un aposento más digno de su nueva estructura que el de un simple casillero en la parte especial del Derecho Administrativo"32. En su opinión el Urbanismo se transforma en Derecho urbanístico mediante la juridificación de sus normas técnicas, es decir, cuando estas comienzan a irradiar, sobre las conductas, un criterio de licitud, pues estas permiten dar respuesta a un complejo de valores y de derechos de elevado rango que podrían quedar gravemente comprometidos si esa actividad no fuese regulada o controlada33. "De allí que el Derecho urbanístico, más que crear normas reguladoras de la actividad urbanística, selecciona y recoge grupos normativos coherentes, elaborados por el Urbanismo, le incorpora técnicas jurídicas (sanciones, recursos, plazos, procedimientos, estructura y estilo) y les reviste de carácter vinculante propio del Derecho, con la mira de preservar aquellos valores y de armonizar el recto ejercicio de los derechos señalados, así como de asegurar, también, el cumplimiento de los deberes correlativos" 34 .

Para otros, como Enrique Rajevic, no es posible hablar en Chile de un Derecho urbanístico como disciplina autónoma, al menos en el estadio actual en el que se encuentra ${ }^{35}$, a pesar del esfuerzo meritorio que se ha hecho para reconstruir dogmáticamente esta disciplina a partir de sus principios fundamentales a la luz del Derecho chileno ${ }^{36}$.

En nuestra opinión, la existencia del Derecho urbanístico como disciplina jurídica no es discutida. Tampoco se discute su pertenencia al ámbito del Derecho público y, dentro de este, al Derecho Administrativo. Sin embargo, pensamos que su contenido no solo es una proyección de los conceptos y categorías dogmáticas que emanan de dicha disciplina, sino que se integran en una trama que permite vislumbrar un sistema que se construye sobre la base de principios que son propios y que la dan una identidad singular: regulación administrativizada a través de instrumentos de planificación territorial que son vinculantes; la potestad de establecer distintos regímenes o estatutos del suelo mediante su clasificación en área urbana o rural; intensa intervención administrativa en la ejecución de las obras de urbanización y de edificación; fiscalización en el cumplimiento

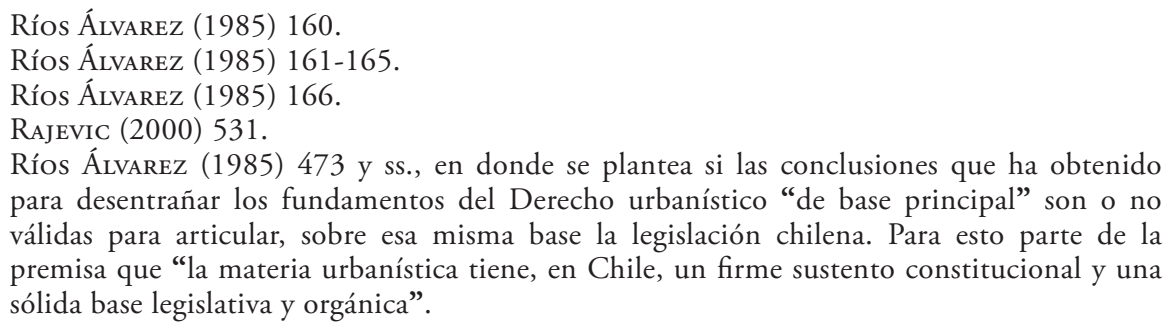
para desentrańar los fundamentos del Derecho urbanístico "de base principal” son o no válidas para articular, sobre esa misma base la legislación chilena. Para esto parte de la premisa que "la materia urbanística tiene, en Chile, un firme sustento constitucional y una sólida base legislativa y orgánica”. 
de la normativa urbanística; facultades para restablecer la legalidad y la existencia de infracciones y sanciones de naturaleza administrativa.

En definitiva, existe un conjunto de normas que regulan todo el tracto o proceso de decisiones públicas que van desde el diseño de un modelo territorial futuro y que llegan a su materialización en la forma de crear y recrear la ciudad, y que se despliega en un conjunto de potestades públicas que se atribuyen a diversos órganos que integran la Administración del Estado ${ }^{37}$. Existen entidades, normas, procedimientos, actos y mecanismos de control de naturaleza administrativa, pero que mirado en su conjunto conforman un sistema que responde a ciertos principios que emanan de una parte del ordenamiento jurídico encabezado por la Constitución. El Derecho urbanístico es Derecho administrativo, pero que conforma un sistema que hace que los principios que provienen desde su rama matriz adquieran una singularidad y sentido, que solo se comprende como un tramado que tiene por objeto alcanzar ciertos valores y bienes jurídicos mediante la regulación de los usos y actividades que se pueden desarrollar en el suelo.

\section{4) Derecho URbanístico, Derecho INMObiliario y Derecho DE LA EDIFICACIÓN}

El Derecho urbanístico aparece estrechamente unido al Derecho inmobiliario y al Derecho de la Edificación o de la Construcción. Por lo demás es el propio legislador el que ha hecho esta estrecha vinculación, al regular el Urbanismo y Construcción de forma conjunta desde 1929 a la fecha. Por lo tanto, de inmediato surge la pregunta sobre cuál sería la relación que existe entre una y otra disciplina.

Tal como hemos señalado, el Derecho urbanístico tiene por objeto aquellos principios y normas que regulan la forma de hacer ciudad, es decir, la actividad administrativa encaminada a determinar la ordenación del espacio, los usos del suelo, la ejecución material de las obras de urbanización y de edificación. Por lo tanto, en su parte final la edificación constituye el hito que marca el cierre de un ciclo que se inicia desde la planificación urbana. El Derecho urbanístico se ocupa de todo el proceso que permite contar con unidades de suelo que puedan ser edificadas, determinando el contenido material efectivo del derecho de propiedad en cada una de dichas unidades. Una vez que se alcanza dicho objetivo, su función se limita a garantizar el cumplimiento de la legalidad urbanística, más no a hacerse cargo de las relaciones jurídico-privadas que surgen de la

37 Cordero (2008a) 95. 
edificación y de los posteriores actos de adquisición, transferencia y disposición del mismo.

En efecto, la legislación urbanística desarrolla un sistema que tiene por finalidad una utilización racional del suelo, utilizando la ordenación como principal instrumento para resolver esta necesidad. Dicha finalidad e instrumento se aplican a dos fenómenos claramente diferenciados dentro del urbanismo: a) el uso y la edificación sobre una espacio determinado; y b) la urbanización, entendida como el conjunto de obras necesarias para la creación de una estructura urbana óptima, que permita la existencia de unidades de suelo sobre los cuales se pueda edificar. Ambos fenómenos pueden ir de la mano (cuando el planeamiento desencadena antes de su aplicación a los usos y actos de edificación en unidades suelo, todo un proceso de "ejecución", con el desarrollo de un nuevo tejido urbano o modificación del ya existente), pero nada obsta, como habitualmente ocurre, que el uso y la actividad de edificación sea independiente y autosuficiente, por contar con obras y servicios urbanos adecuados que permiten al planeamiento asumir dicha realidad, así como la existencia de unidades edificables. En este caso, la ordenación urbanística se limitará a refrendar esta realidad y a regular la intervención administrativa en el ámbito del uso y edificación de unidades concretas de suelo o terreno.

En efecto, la materialización de la ordenación urbana puede tener lugar con la simple aplicación de sus normas contenidas en los planes, ya que estas pueden ser una refrendación del orden ya existente, permitiendo de inmediato el ejercicio del derecho a edificar. En otros casos, será necesario una transformación del suelo mediante la urbanización, que es una tarea previa a la existencia de unidades de suelo edificable. Una vez que aquellas se han materializado, surge un producto ex novo: suelo edificable, lo cual marca en parte el término del Derecho urbanístico y el inicio del Derecho de la Edificación y el Derecho inmobiliario.

A su vez, el Derecho de la Edificación comprende el conjunto de normas que regula el proceso de edificación, esto es, la acción y resultado de construir un edificio de carácter permanente o temporal. Este caso se ocupa de los agentes que intervienen en la construcción, estableciendo sus obligaciones, el régimen de responsabilidad y las garantías.

Por su parte, el Derecho inmobiliario es parte del Derecho civil patrimonial y comprende todas aquellas normas que dicen relación con las formas de adquisición, administración y disposición de los bienes inmuebles, así como las formas de organización de la misma.

De esta forma es posible distinguir el Derecho urbanístico dentro del ámbito del Derecho público, frente al Derecho de la Edificación y al Derecho inmobiliario, que son residenciados en el ámbito del Derecho privado de carácter patrimonial. 


\section{5) CONTENIDOS Y PRINCIPIOS DEL DERECHO URBANÍSTICO}

Establecida la naturaleza del Derecho urbanístico y los elementos que lo distinguen de otras disciplinas, nos corresponde establecer cuál sería el contenido de esta rama del Derecho (5.1) y cuáles serían los principios sobre los cuáles se construye (5.2).

\section{1) CONTENIDO DEL DERECHO URBANÍSTICO}

El contenido del Derecho urbanístico comprende las diversas instituciones que resumen las formas de actuación de los órganos administrativos para proyectar un orden de las actividades dentro del espacio y garantizar que este sea respetado y cumplido por los destinatarios, lo cual se expresa en potestades concretas, como planificación y la intervención administrativa en la edificación y uso del suelo.

En la actualidad el Derecho urbanístico chileno comprende los siguientes contenidos:

\subsection{1) La Planificación Urbana}

Nuestro ordenamiento establece que la Planificación Urbana es un el proceso que se efectúa para orientar y regular el desarrollo de los centros urbanos en función de una política nacional, regional y comunal de desarrollo socioeconómico ${ }^{38}$. Si bien dicho proceso se debería efectuar en cuatro niveles (nacional, regional, intercomunal y comuna), en la práctica solo ha alcanzado los tres últimos, ya que a nivel nacional solo se han elaborado políticas y no planes ${ }^{39}$.

En esta materia, el Decreto Supremo No 46, de 1992, del Ministerio de Vivienda y Urbanismo, contiene la Ordenanza General de Urbanismo y Construcciones (OGUC), que constituye el reglamento que complementa y desarrolla a la Ley General de Urbanismo y Construcciones contenido en el Decreto con Fuerza de Ley No 458, de 1975 (LGUC). A este respecto, utiliza un concepto más amplio de "Instrumento de Planificación Territorial" los cuales tienen los siguientes niveles de acción:

\footnotetext{
38 Artículo 27 LGUC.

39 En Chile se ha optado por su sustitución a través de "Políticas Nacionales de Desarrollo Urbano", bajo la forma de una circular directiva que tiene por función fijar objetivos que guíen la actuación de los órganos a los cuales se les atribuye potestades sectoriales de incidencia territorial, así como a las entidades territoriales, que deben coordinar su actuación con las políticas nacionales. Este instrumento es dictado conforme a lo dispuesto en el art. 8 del DL. No 1.305 que encomienda al Ministro de Vivienda y Urbanismo "la formulación de la política nacional habitacional y urbanística del Gobierno”. La última política nacional de desarrollo urbano ha sido aprobada en Chile en octubre del año 2013.
} 
- Plan Regional de Desarrollo Urbano

- Plan Regulador Intercomunal o Metropolitano

- Plan Regulador Comunal con sus planos seccionales que lo detallen

- Plan Seccional

- Límite Urbano ${ }^{40}$

El contenido de dichos instrumentos varía según el nivel de planificación. Así, el Plan Regional de Desarrollo Urbano (PRDU) está orientado el desarrollo de los centros urbanos de las regiones; el Plan Regulador Intercomunal o Metropolitano (PRI o PRM) regulan el desarrollo físico de las áreas urbanas y rurales de diversas comunas que, por sus relaciones, se integran en una unidad urbana; el Plan Regulador Comunal (PRC) promueve el desarrollo armónico del territorio comunal, en especial de sus centros poblados, en concordancia con las metas regionales de desarrollo económico-social; y los Planes Secciones son instrumentos de regulación del uso del suelo a través de los cuales se desarrolla un PRC o se lleva a cabo una ordenación autónoma de una parte o sector del territorio municipal. También se considera como un Instrumento de Planificación la fijación del límite urbano, que consiste en "la línea imaginaria que delimita las áreas urbanas y de extensión urbana que conforman los centros poblados, diferenciándolos del resto del área comunal" (artículo 52 LGUC).

En cuanto a su elaboración y aprobación, la OGUC, la Ley No 18.695, Orgánica Constitucional de Municipalidades y la Ley No 19.175, Orgánica Constitucional de Gobierno y Administración Regional, establecen el procedimiento. Este varía, dependiendo del nivel y autoridad que debe intervenir: en los PRC y planes secciones intervienen las Municipalidades y, en determinados supuestos, el Gobierno Regional y la Secretaría Regional Ministerial de Vivienda y Urbanismo; en los PRI, PRM y PRDU interviene Gobierno Regional y la Secretaría Regional Ministerial de Vivienda y Urbanismo.

En cuanto a sus efectos, los Instrumentos de Planificación Territorial son de naturaleza reglamentaria, por lo tanto son vinculantes tanto para los órganos de la Administración como para los particulares, especialmente respecto de la forma como se debe ejercer el ius aedificandi. Así, el artículo 57 LGUC dispone que "el uso del suelo urbano en las áreas urbanas se regirá por lo dispuesto en los Planes Reguladores, y las construcciones que se levanten en los terrenos serán concordantes con dicho propósito". 


\subsection{2) El Régimen urbanístico de la propiedad del suelo}

Los Instrumentos de Planificación del Territorio determinan el régimen urbanístico de la propiedad del suelo y los derechos y deberes básicos de los propietarios. Para tal efecto, realiza una clasificación del suelo a través de la determinación del límite urbano (área urbana y área rural). Posteriormente establece las normas de zonificación del suelo, mediante la definición de subzonas en base a normas urbanísticas sobre usos de suelo, sistemas de agrupamiento de las edificaciones, coeficientes de constructibilidad, coeficientes de ocupación de suelo o de los pisos superiores, alturas máximas de edificación, adosamientos, distanciamientos mínimos a los medianeros, antejardines, ochavos y rasantes; superficie de subdivisión predial mínima, etc.

Esto determina la existencia de distintas clases de suelo y, por tanto, de diversos derechos y deberes básicos de los propietarios:

a) El área urbana en sentido estricto corresponde a lo que se conoce como casco histórico y se caracteriza por disponer de los elementos básicos de urbanización que dan a las unidades de suelo el carácter de parcelas o solares urbanizados sobre los cuales es posible edificar. Los elementos que determinan la urbanización son las calles y pasajes pavimentados, las plantaciones y obras de ornato, las instalaciones sanitarias y energéticas, con sus obras de alimentación y desagües servidas y de aguas lluvia, y las obras de defensa y servicio del terreno ${ }^{41}$. Tal como lo hemos señalado, el uso del suelo urbano en las áreas urbanas se regirá por lo dispuesto en los Planes Reguladores y las construcciones que se levanten en los terrenos serán concordantes con dicho principio. De esta forma, el propietario de suelo urbano existente solo está sometido a las normas de uso y edificación que comprende, entre otras materias, aspectos como la zonificación, densidades, tipología de edificación, altura de los edificios y porcentaje de ocupación de la superficie del suelo.

b) El área de extensión urbana son reservas de espacio consideradas en los instrumentos de planificación territorial para el futuro crecimiento, mediante la creación de una o más áreas de extensión, adyacentes al área urbana. En la actualidad, aparecen reguladas en la OGUC, que las define como el "área territorial establecida en los Instrumentos de Planificación Territorial destinada a la extensión del área urbana” (art. 1.1.2. OGUC). Corresponde al Plan regulador intercomunal la definición de los límites de extensión urbana, para los efectos de diferenciar el área urbana del resto del territorio, que se denominará área rural (artículo 2.1.7. OGUC). Esta área solo aparece mencionada en la LGUC en sus artículos 35 y 52, a propósito de los contenidos del Plan Regulador Intercomunal y de los

41 Artículo 134 LGUC. 
límites urbanos, pero no se contienen normas concretas que determinen su programación y desarrollo. De algunos preceptos (artículos 52 y 55 LGUC y arts. 2.1.7. y 2.1.20 OGUC) parece desprenderse que las áreas de extensión urbana son una parte del suelo urbano sujeto a programación temporal, pero esto no está del todo claro. De hecho, su existencia y desarrollo posterior está sujeto a lo que disponga los instrumentos de planificación. Por su parte, la Contraloría General de la República ha sostenido en su Dictamen No 2.373, de 23 de enero de 1984, que las áreas de extensión urbana son parte del área urbana: "[...] el artículo 52 de la Ley General de urbanismo y Construcciones entiende por "límite urbano, para los efectos de la presente ley y de la Ley Orgánica de Municipalidades, la línea imaginaria que delimita las áreas urbanas y de extensión urbana que conforman los centros poblados, diferenciándolos del resto del área comunal". De este modo, la expresión "límite urbano" se encuentra definida por ley y con arreglo al artículo 20 del Código Civil deberá dársele siempre el significado que aquella le asigna. [...] en todas las comunas del país en que se haya establecido límite urbano, éste separa en dos porciones claramente diferenciadas el territorio comuna: en una se encuentran las superficies urbanas ya consolidadas (áreas urbanas) como también las que son susceptibles de dicha urbanización (áreas de extensión urbana). Y en la otra, el resto de área comunal, que los artículos 55 y 56 de la Ley General llaman rural. Dicho de otro modo: el límite urbano constituye la frontera que separa el territorio que es lícito someter al uso urbano de aquél en que la ley, de modo general, veda dicha posibilidad" 42 .

El aspecto más importante de esta área es que se trata de suelo no urbanizado, de forma que se impone al propietario dos obligaciones básicas: a) el deber de urbanizarlos (artículos 134 y ss. LGUC), como requisito previo para la edificación y disposición de unidades edificables que resulten de dicho proceso; y b) la obligación de ceder gratuitamente parte de los terrenos a circulación, áreas verdes y equipamientos, cuyo porcentaje es establecido por la OGUC ${ }^{43}$. Como contrapartida el propietario-urbanizador patrimonializa la totalidad del ius aedificandi atribuido por el plan siempre que se materialice a través de la edificación ${ }^{44}$.

42 En el mismo sentido se pueden ver el Dictámenes Nos. 39.068, de 1995, y 21.289, de 1996.

43 Artículo 2.2.5 OGUC.

44 Estas áreas han dado pie para que, por la vía de los instrumentos de planificación, específicamente a través del Plan Regulador Metropolitano de Santiago en una modificación introducida en 1997, se crearan las denominadas "Zonas Urbanizables con Desarrollo condicionado" (ZODC), que se caracterizan por ser zonas de baja densidad edificatoria, pero que permiten a los propietarios obtener un mayor aprovechamiento cumpliendo una serie de condiciones. De esta manera, se están introduciendo en Chile algunas figuras que tienden a atenuar la rigurosidad de la mera aplicación de la norma, a través de mecanismo de programación y flexibilización en la transformación del suelo, dando a los propietarios un papel preponderante en este tipo de decisiones. 
c) Por último, se encuentra el área rural que está comprendida fuera de los límites urbanos establecidos en los Planes Reguladores, por tal razón, su régimen jurídico constituye la regla general. En este suelo no está permitido abrir calles, subdividir para forma poblaciones, ni levantar construcciones, salvo aquellas que fueren necesarias para la explotación agrícola del inmueble, o para las viviendas del propietario del mismo y sus trabajadores, o para la construcción de conjuntos habitacionales de viviendas sociales o de viviendas de hasta un valor de 1.000 unidades de fomento, que cuenten con los requisitos para obtener el subsidio del Estado. Excepcionalmente se pueden autorizar la subdivisión y urbanización de terrenos rurales para complementar alguna actividad industrial con viviendas, dotar de equipamiento a algún sector rural o habilitar un balneario o campamento turístico, y para la construcción de conjuntos habitacionales de viviendas sociales o de viviendas de hasta un valor de 1.000 unidades de fomento, que cuenten con los requisitos para obtener el subsidio del Estado. En este caso se requiere la aprobación por parte de las SEREMIS de Agricultura y Vivienda, sin perjuicio de la aprobación del permiso correspondiente por parte de la DOM.

\subsection{3) La gestión urbanística: la ejecución del planeamiento}

La gestión urbanística dice relación con las formas o modalidades de ejecución del planeamiento. Tenemos que tener presente que los planes reguladores no solo son normas que regulan la forma de hacer ciudad y edificar, sino también son instrumentos de planificación orientados a materializar un determinado modelo de ordenación territorial.

Las modalidades de ejecución de planeamiento pueden variar, dependiendo de la mayor o menor intervención del aparato público. Al mismo tiempo, también va a depender de la forma en que dicha ejecución se realice, ya sea de forma aislada o concreta (ejecución asistemática) o en el marco de un proceso global y ordenado (ejecución sistemática).

En efecto, en el primer caso la ejecución del planeamiento implica el cumplimiento de las normas que en él se contiene de forma aislada, es decir, al momento en que cada propietario toma la decisión de ejercer su derecho conforme a las normas del plan, debiendo asumir las obligaciones o cargas que él mismo le impone para cada caso en particular (cesiones, urbanización, etc.), sin considerar la forma o modo en que los demás propietarios lo van ejercer o no, así como las cargas que se deben asumir desde una perspectiva global respecto de la forma de hacer ciudad. En estos casos la posibilidad de llevar adelante este proceso es una decisión entregada a cada propietario, mientras que la economía del mismo (derechos y cargas) solo mira la situación particular de aquellos, considerando los usos, edificabilidad, cesiones y urbanizaciones a realizar. Bien puede ocurrir que el proyecto sea altamente rentable (alta edificabilidad y pocas cargas) o muy 
inconveniente de llevar adelante (poca o nula edificabilidad y altas cargas), porque no existe un proceso de redistribución entre todos los propietarios de estos beneficios y cargas. A consecuencia de lo anterior, se produce una clara desigualdad entre aquellos que han sido beneficiados por el planificador, respecto de aquellos cuyos terrenos deben soportar los espacios públicos y dotaciones que requiere la ciudad. Además, los mecanismos de incentivo son claramente perversos, ya que solo crean las condiciones para hacer ciudad por parte de los propietarios en los casos en que los beneficios del proceso urbanístico sean altos. En caso contrario, son las entidades públicas las que deben asumir el costo que esto significa, ya sea mediante la expropiación de los terrenos y la construcción de los elementos urbanos necesarios para ejercer el derecho a edificar. Así, la ejecución asistemática no constituye un mecanismo apropiado para colocar de cargo de los propietarios la posibilidad de hacer ciudad y genera enormes desigualdades en los beneficios y cargas que genera el proceso urbano.

Por su parte, en un modelo de ejecución sistemática del planeamiento se establecen diversas formas de actuación que permiten llevar adelante el proceso urbanístico desde una dimensión global, lo cual comprende la producción de espacios urbanos y de unidades edificables considerando todos los beneficios y cargas que estas generan. La regulación de la misma puede llevar a diversas alternativas, las que van desde aquellas que le dan un rol preponderante a la autoridad pública (expropiación, construcción de la obra pública urbana necesaria, producción de suelo edificable y enajenación de los mismos) o se establecen mecanismos de incentivo a los particulares para participar en el proceso urbano mediante formas de compensación por los beneficios y cargas, siempre con el apoyo de la autoridad considerando que se trata de una función pública, todo lo cual es sin perjuicio que el incentivo final se encuentra en el ejercicio del derecho a edificar. Tradicionalmente estos se han clasificado como formas de gestión urbanística pública, privada o mixta. La actuación es pública cuando se realiza sobre suelo público por parte de la propia autoridad, ya sea del patrimonio público u obtenidos por expropiación; es privada en los casos en que la gestión es realizada por privados en suelo privado, asumiendo los costos y beneficios del mismo bajo el control de la autoridad pública; y es mixta cuando interviene la Administración y los particulares sobre suelo privado, ya sea mediante la construcción de obras públicas por las entidades públicas, el financiamiento por los particulares, las cesiones que deben realizar estos últimos, etc. ${ }^{45}$.

Ahora bien, en Chile no se contemplan sistemas de ejecución sistemática del planeamiento, de manera que su aplicación se realiza solo de forma asistemática. Con esto queremos señalar que la ejecución o materialización de las normas de planificación urbana, esto es, la urbanización 
efectiva y posterior edificación, están entregadas a los particulares y, excepcionalmente, al Estado, sin que exista algún sistema legal y obligatorio de acción concertada tanto pública o privada en este sentido. De esta manera, los propietarios del suelo están sujetos a los instrumentos de planificación urbana o planes reguladores como lo estarían frente a cualquier otra norma jurídica, es decir, se encuentran en una suerte de sujeción general. No existen planes fijados temporalmente y, menos aún, entidades urbanísticas o sistemas de administración delegada en la gestión en que tengan participación los propietarios del suelo ${ }^{46}$. Así, para la ejecución del plan es requisito sine qua non tener la calidad de propietario o contar con el asentimiento de los propietarios, con el objeto de llevar adelante las obras de urbanización, cediendo el suelo para las dotaciones (viales, áreas verdes, etc. $)^{47}$. La expropiación solo se ejerce de forma excepcional, no pudiendo constituir un sistema de ejecución, pues está reservado para la obtención del suelo necesario destinado a áreas de uso público y de equipamientos ${ }^{48}$.

46 En una situación distinta se encuentran los Servicios Regionales de Vivienda y Urbanización (SERVIU), cuya participación en la ejecución de los instrumentos de planeamiento es solo parcial. Los SERVIU son organismos ejecutores a nivel regional de las políticas, planes y programas que disponga desarrollar el Ministerio de Vivienda y Urbanismo, y, como tal, no tienen facultades de planificación (artículos 25 del Decreto Ley No 1.305, de 1976, que Reestructura y Regionaliza el Ministerio de Vivienda y Urbanismo y artículo $1^{\circ}$ de Decreto Supremo No 355, de 176, que aprueba el Reglamento Orgánico de los Servicios de Vivienda y Urbanización). La función de los SERVIU esta vinculada principalmente a la construcción de viviendas sociales, así como de obras comunitarias. En este sentido, el SERVIU está encargado de adquirir terrenos, efectuar subdivisiones prediales, formar loteos, proyectar y ejecutar urbanizaciones, proyectar y llevar a cabo remodelaciones, construir viviendas individuales, poblaciones, conjuntos habitacionales y barrios, obras de equipamiento comunitario, formación de áreas verdes y parques industriales, vías y obras de infraestructura y, en general, cumplir toda otra función de preparación o ejecución que permita materializar las políticas de vivienda y urbanismo y los planes y programas aprobados por el Ministerio (artículos 27 y 28 del Decreto Ley No 1.305, de 1976, que Reestructura y Regionaliza el Ministerio de Vivienda y Urbanismo y artículo $3^{\circ}$ Decreto Supremo No 355, de 176, que aprueba el Reglamento Orgánico de los Servicios de Vivienda y Urbanización).

47 En este sentido el art. 134 LGUC establece que "para urbanizar un terreno, el propietario del mismo deberá ejecutar, a su costa, el pavimento de las calles y pasajes, las plantaciones y obras de ornato, las instalaciones sanitarias y energéticas, con sus obras de alimentación y desagües de aguas servidas y de aguas lluvias, y las obras de defensa y servicio de terrenos".

48 Artículo 83 LGUC. Lo dicho es sin perjuicio de las facultades que tienen los SERVIU, que están autorizados para expropiar los inmuebles que sean indispensables para la ejecución de los programas de construcción de viviendas, equipamiento comunitario, obras de infraestructura y remodelaciones que apruebe el MINVU (art. $4^{\circ}$ y artículos 53 a 58 del Decreto Supremo No 355, de 176, que aprueba el Reglamento Orgánico de los Servicios de Vivienda y Urbanización), pero como ya lo hemos dicho, su actuación en la ejecución de planeamiento es solo parcial. 


\subsection{4) La disciplina urbanística}

La disciplina urbanística comprende las viejas técnicas de policía urbana destinada a velar por el cumplimiento de la legalidad urbanística, particularmente aquella contenida en los planes reguladores. Esta se expresa en los siguientes instrumentos:

a) El control en la ejecución de las obras de urbanización y de edificación a través de la técnica autorizatoria, que se concreta en el denominado "permiso de urbanización o edificación", según el caso $^{49}$;

b) En las inspecciones y recepciones de obras;

c) En la fiscalización del cumplimiento de las normas sobre seguridad y conservación de las edificaciones ${ }^{50}$;

d) El restablecimiento de la legalidad (paralización de obras, demoliciones) $)^{51}$, y

e) En la existencia de un conjunto de infracciones y de sanciones ${ }^{52}$.

\subsection{5) Síntesis del contenido del Derecho urbanístico}

Conforme a lo hemos expuesto, el contenido del Derecho urbanístico chileno puede ser resumido en los siguientes cuatro puntos:

a) La Planificación urbanistica, que comprende las clases de planes; contenido; elaboración y aprobación; y efectos;

b) El Régimen urbanistico de la propiedad del suelo, que abarca la clasificación y zonificación urbanística; el régimen de las clases de suelo; y los derechos y deberes básicos de los propietarios y expropiación;

c) La Gestión urbanistica, que está vinculada a las formas de ejecución del planeamiento; y

d) Disciplina urbanistica, que comprende la intervención preventiva de la edificación y uso del suelo (licencias, órdenes de ejecución, ruina, protección de la legalidad urbanística, parcelaciones e inspección urbanística) e infracciones y sanciones (Derecho urbanístico sancionador).

\footnotetext{
49 El artículo 116.1. LGUC establece que "la construcción, reconstrucción, reparación, alteración, ampliación y demolición de edificios y obras de urbanización de cualquier naturaleza, sean urbanas o rurales, requerirán permiso de la Dirección de Obras Municipales".

Artículo 142 LGUC.

Artículos 146 y 148 LGUC.

Artículos 20 y 21 LGUC.
} 


\section{2) Principios del Derecho Urbanístico}

El recurso a los principios como instrumentos para establecer las reglas básicas de conducta o sistematizar las líneas maestras sobre las cuales se construye un determinado ordenamiento jurídico no es algo nuevo, aunque se debe reconocer que su uso se ha ido acentuado a tal punto que, en muchos casos, constituyen las pautas o criterios determinantes utilizados por los operadores jurídicos al momento de resolver los casos sometidos a su conocimiento.

En efecto, en la actualidad constituye una práctica habitual en la doctrina nacional el recurso a los mismos y es una importante fuente utilizada por parte de los operadores jurídicos más relevantes en el ámbito jurídico-administrativo, como sucede con la Contraloría General de la República, el Tribunal Constitucional y los Tribunales Superiores de Justicia, labor en la que también se ha incorporado el legislador atenuando la densidad prescriptiva de sus regulaciones e incorporando derechamente la expresión "principios" en textos normativos de suma relevancia para la actividad administrativa ${ }^{53}$. Sin embargo, también los principios jurídicos producen una suerte de paradoja, en la medida que permiten superar el legalismo extremo, constituyendo un notable avance para llegar a soluciones razonables y justas a partir del espíritu general que parece emanar de las normas positivas, pero por otra parte nos producen cierta inseguridad e incertidumbre, dado que se trata de pautas generales que orientan el obrar humano y que muchas veces dejan la puerta abierta a diversas posibilidades de actuación y/o resolución por parte de los órganos administrativos y jurisdiccionales. Bien se ha dicho por Alejandro Nieto que el resultado final puede parecer sorprendente y provocar la repulsa de honestos juristas, al cuestionar cierta falacia que existe en esta forma de proceder, siempre con una acertada ironía: "el Derecho progresa cuando renuncia a sus caracteres aparentemente esenciales de claridad y previsibilidad y cuando debilita la garantía de la seguridad jurídica que ofrecen sus normas positivas, para lanzarse a las turbulencias vitales y arriesgadas de los principios generales del Derecho" 54 .

Ahora bien, en este caso nuestro interés se centra solo en una de las tantas funciones que cumplen los principios jurídicos: como aporte a la dogmática jurídica para sistematizar un sector del ordenamiento jurídico, interpretar las normas que lo conforman y llenar aquellas insuficiencias

\footnotetext{
53 En este punto destaca el artículo $3^{\circ}$ de la Ley No 18.575, Orgánica Constitucional de Bases Generales de la Administración, después de la modificación introducida por la Ley No 19.653; los artículos $4^{\circ}$ y ss. de la Ley No 19.880, que establece las bases de los procedimientos administrativos que rigen los actos de los órganos de la Administración del Estado o el artículo $7^{\circ}$ de la Ley No 20.285, de acceso a la información pública.

54 Nieto, Alejandro (2011). Derecho administrativo sancionador. 4 ed. Madrid: Tecnos, p. 42.
} 
que pudiesen existir en su regulación. En definitiva, se trata de una función de sistematización, interpretación e integración de una parte del ordenamiento jurídico, como es el Derecho urbanístico.

Lautaro Ríos Álvarez enuncia lo que denomina "principios jurídicos especiales del Derecho urbanístico", partiendo desde los principios generales del derecho, pero que serían en este caso una guía para la conformación de una rama del ordenamiento o de un área determinada del tráfico jurídico, sin que tengan aptitud "normogénica" en los restantes campos del derecho ${ }^{55}$. A partir de un análisis comparado de los países de Europa occidental y de la legislación de estados americanos, da cuenta de un conjunto de principios comunes que luego aplica a nuestro ordenamiento. Estos principios serían: i) el principio de legalidad, tanto en la organización de los órganos administrativos como en sus competencias; ii) el principio de planificación, como requisito legitimante de toda la actividad urbanística; iii) el principio de la función social de la propiedad; iv) el principio de igualdad en el reparto de beneficios y de las cargas urbanísticas; y v) el principio de participación de los administrados ${ }^{56}$.

Si bien compartimos buena parte de los principios formulados por Lautaro Ríos, desde el punto de vista metodológico y de su contenido, pensamos que aquello debe partir de la premisa que el Derecho urbanístico forma parte del Derecho público y en particular del Derecho administrativo. Por tal razón, no es de extrañar que participe de los principios generales de esta disciplina, aunque con ciertos matices que le dan su propia fisonomía o singularidad. En el mismo sentido, esto implica que las normas urbanísticas no sean un cuerpo aséptico o neutro, como bien lo platea Ríos Álvarez al afirmar que deben preservar ciertos valores (igualdad, seguridad, justifica distributiva, la digna calidad de vida y la belleza de la ciudad), así como el recto ejercicio de derechos y deberes correlativos (la propiedad, libre empresa, el derecho a la vivienda adecuada y a su entorno, el igual reparto de beneficios y cargas, el derecho a la vista, el asolamiento, al aire puro, etc.), aunque no necesariamente será una suerte de juridificación de normas de naturaleza técnica como afirma el mismo autor, ya que tienen un componente sustantivo que nace de su integración en el ordenamiento jurídico a partir de sus bases esenciales.

Así, respecto de los valores y principios de servicialidad, bien común, integración armónica de todos los sectores de la Nación, el derecho de las personas a participar con igualdad de oportunidades en la vida nacional, medio ambiente libre de contaminación y conservación del patrimonio ambiental, se traduce en que el urbanismo sea una función pública al momento de adoptar las decisiones fundamentales respecto del crecimiento y

\footnotetext{
55 Ríos Állvarez (1985) 259 y ss.

56 Ríos Álvarez (1985) 263-264.
} 
desarrollo de las ciudades, sin desconocer la función que les puede corresponder a los particulares en la materia.

A su vez, el principio de legalidad adopta un matiz particular con la existencia de órganos que conforman la Administración Urbanística, dotados de un conjunto de atribuciones y potestades (planificación, autorización, fiscalización y sanción), con las singularidades propias de dichas actuaciones (presunción de legalidad, imperio y ejecutividad). Además, se conforma un marco de legalidad en el cual se integran instrumentos de planificación territorial, que son expresión de una política urbana, tienen carácter normativo y configuran el régimen objetivo del derecho de propiedad del suelo, conforme al cual los propietarios podrán incorporar en su patrimonio los usos y facultades urbanísticas.

La función social de la propiedad se traduce en este caso en la existencia de una pluralidad de estatutos (pluralidad de propiedades), que conforme a los instrumentos de planificación determinan distintas clases de suelo (urbano y rural), con sus diferentes derechos, cargas y obligaciones.

A su vez, la garantía de la integridad patrimonial se asegura mediante el reconocimiento y protección de los derechos adquiridos conforme a los instrumentos de planificación territorial, a través de diversas técnicas que reconoce nuestra legislación.

Los fundamentos o elementos estructurales básicos del Derecho urbanístico chileno se pueden comprender mejor a la luz de siguientes principios: i) el urbanismo como función pública; ii) la legalidad urbanística y las potestad de planificación; iii) la función social de la propiedad y la pluralidad de estatutos; y iv) el reconocimiento y protección de los derechos adquiridos conforme a los instrumentos de planificación territorial.

Algunos autores consideran también la aplicación del principio de igualdad, especialmente en su versión de una justa distribución de los beneficios y cargas que derivan de la acción urbanística de los poderes públicos, sin embargo, nosotros pensamos que aquello es discutible ${ }^{57}$. En primer lugar, porque la planificación urbanística supone la creación de desigualdades respecto de las clases de suelo, los usos y la edificabili$\mathrm{dad}^{58}$. En segundo término, porque no existen en el ámbito estrictamente

57 Guillmore y Guerrero (2001) 33-36, aunque lo limitan a la posibilidad de acuerdos con la autoridad. Por su parte, Ríos Álvarez (1985) 353 y ss. expone la situación en el Derecho español y en el caso chileno se limita a constatar la situación ya señalada, indicando que "probablemente esta carencia de regulación legislativa se debe a que -no existiendo mecanismos complejos de intervención administrativa susceptibles de ocasionar desigualdades- no ser requieren disposiciones que, precisamente, estén destinadas a nivelarlas. En cambio, Figueroa (2006) 72-75, lo vincula a un problema de protección del contenido esencial del derecho de propiedad, vinculadas a la idea de una igual y racional distribución de cargas urbanísticas.

58 Situación reconocida, por lo demás, por la doctrina nacional: Ríos Álvarez (1985), 353 y ss. y Guillmore y Guerrero (2001) 32. 
urbanístico alguna fórmula de perecuación o equidistribución de los beneficios y cargas que genera la acción urbanística en Chile, de tal forma que las desigualdades creadas por el plan no cuentan con mecanismos de compensación de cargas y beneficios.

No obstante lo anteriormente, el principio de igualdad constituye una importante limitación a la potestad de planificación, así como a las cargas que esta impone, ya que las diferencias que genera la acción urbanística no pueden ser arbitrarias y menos aún pueden significar un menoscabo patrimonial para los propietarios.

Nos corresponde ahora dar cuenta en general de cada uno de estos principios, con el objeto de determinar su contenido y alcance en nuestro Derecho.

\subsection{1) El urbanismo como función pública}

Uno de los aspectos centrales del Derecho urbanístico es determinar la naturaleza y función que se le asigna al urbanismo como función. Esta es una cuestión que muchas veces ha sido preterida en los trabajos que se han escrito en Chile, pero que ha ido siendo asumida por la doctrina nacional del último tiempo ${ }^{59}$.

Lo cierto es que la actividad urbanística ha estado estrechamente asociada en Chile a la promoción privada, existiendo una percepción de la actividad administrativa por parte de la comunidad y de los agentes económicos más bien secundaria en esta materia, incluso incómoda y burocrática $^{60}$.

Ahora bien, tal como se ha señalado el urbanismo cumple dos funciones básicas: a) determinar las normas de uso y edificación sobre el suelo, y b) puede desencadenar un proceso de transformación del suelo para incorporarlo a la ciudad, mediante la creación de unidades de suelo edificables mediante el proceso de urbanización. Hasta este nivel estamos en el marco de la función pública del urbanismo y comienza una nueva etapa que es la edificación.

Figueroa (2006) 6 y 7.

Un buen ejemplo lo constituye la política de liberalización del suelo emprendida a fines de la década de los 70 del siglo pasado, que postulaba un sistema de planificación flexible con el mínimo de intervención estatal. Sobre esta materia véase Ministerio de Vivienda y Urbanismo (1981) "Política Nacional de Desarrollo Urbano, y Conceptos básicos para la formulación de una Política Nacional de Desarrollo Urbano”. EURE, vol. II, No 22, septiembre, pp. 9-15; PARrochia B. Juan (2001) "Iniciativas sobre Desarrollo Urbano enunciadas por el Ministerio de Vivienda y Urbanismo, marzo de 1979". Revista de Urbanismo, Universidad de Chile, Facultad de Arquitectura, No 4, julio; AAVV (1999) Seminario Internacional "A 20 Años de la Liberalización de los Mercados de Suelo Urbano en Chile". 7 y 8 de octubre, 1999. Santiago: Cámara de Diputados de Chile; Rajevic (2000) 543-545. 
En nuestro ordenamiento la primera función la cumplen los instrumentos de planificación territorial, cuya elaboración, discusión y sanción está entregada a los órganos que forman parte de la Administración del Estado: Municipalidades, Gobiernos Regionales y Secretarías Regionales Ministeriales de Vivienda y Urbanismo, que son los que determinan en el marco de una política urbana, las normas sobre uso del suelo y de edificación. En esta etapa no les cabe ninguna función decisión a los propietarios.

Por su parte, la segunda función la constituye el proceso de urbanización, en donde se produce una retracción de los órganos públicos y pasan a tener una función determinante los propietarios, en quienes descansa de forma prevalente la decisión de llevar adelante los procesos de urbanización y de transformación del suelo. En efecto, la legislación urbanística chilena no ha publificado en todos sus extremos esta actividad, contemplada en el marco de la gestión urbanística. A diferencia de otros ordenamientos, y tal como lo hemos señalado in supra, no contamos con sistemas públicos que permitan la ejecución sistemática del planeamiento. En tal sentido, este proceso se lleva por regla general de forma asistemática, es decir, queda entregado a la voluntad de los propietarios del suelo, quienes deciden si aplican o no las normas contenidas en los instrumentos de planificación territorial y materialización el proceso de transformación de suelo para permitir la existencia de unidades edificables.

Esto explica, además, el hecho de que la gran mayoría de los estudios de Derecho urbanístico en Chile se hayan centrando en los instrumentos de planificación y sus efectos, mientras que la ejecución del planeamiento es considerada una actividad económica privada encauzada por la normativa urbanística (incluidos los planes reguladores o de ordenación), bajo la concepción tradicional de la antigua actividad de policía urbana.

Sin embargo, el proceso de urbanización constituye un elemento central en la configuración del estatuto de los propietarios, ya que desencadena las cargas de cesión y urbanización del suelo como condición previa y necesaria para la edificación. Por lo demás, no es posible desconocer la intensa intervención que ejercen los órganos administrativos en el proceso de ejecución de las obras de urbanización y de edificación a través de la técnica autorizatoria (permisos de urbanización y edificación); en las inspecciones y recepciones de obras; en la fiscalización del cumplimiento de las normas sobre seguridad y conservación de las edificaciones; así como el restablecimiento de la legalidad (paralización de obras, demoliciones) y la existencia de un conjunto de infracciones y de sanciones.

Por lo tanto, en nuestra opinión en Chile el urbanismo constituye una función pública, pues las decisiones básicas sobre la transformación del suelo y la localización de los elementos urbanos (calles, plazas, poblaciones, dotaciones, etc.) están disociadas del derecho de propiedad, definido en el artículo 582 del Código Civil, y se radican en los órganos públicos, principalmente en las entidades territoriales (Municipalidad y Gobiernos 
Regionales) ${ }^{61}$, en el marco del cumplimiento y satisfacción de un orden material de valores previsto en la Constitución.

Lo anterior no obsta a que la publificación del urbanismo en Chile no alcance los niveles y la profundidad de otros ordenamientos. Así, la LGUC reconoce en su artículo $1^{\circ}$ las tres materias básicas del urbanismo: planificación, urbanización y construcción. La planificación, que comprende las decisiones fundamentales sobre la organización de los usos y aprovechamientos del espacio, está entregada, como competencia pública, a los órganos de la Administración pública, mientras que la urbanización y la construcción han sido colocadas en el ámbito de la actividad privada o de los particulares, aunque sujeta a una intensa intervención administrativa.

\subsection{2) El principio de legalidad urbanística}

El principio de legalidad constituye uno de los pilares fundamentales de nuestro Derecho público, y en particular del Derecho administrativo, tal como lo prescriben los artículos $6^{\circ}$ y $7^{\circ}$ de la Constitución, así como el artículo $2^{\circ}$ de la Ley No 18.575 Orgánica Constitucional de Bases Generales de la Administración. Por tal razón, se reconoce su plena aplicación en el ámbito del Derecho Urbanístico, aunque con algunos singularidades que es bueno destacar:

\section{A) La Administración urbanística}

Todos los órganos que integran la Administración Urbanística solo pueden ser creados por ley, tal como lo establece el artículo 64 inc. $4^{\circ}$ No 2 de la Constitución. Así nos encontramos con las entidades que están llamadas a formular las políticas, planes y programas sobre la materia (Ministerio de Vivienda y Urbanismo y sus respectivas Secretarias Ministeriales Regionales); y aquellas que participan en el proceso de planificación urbana (Municipalidades y Gobiernos Regionales) y en la aplicación de sus disposiciones (Direcciones de Obras Municipales).

61 Lo que estamos afirmando no es en nada novedoso. De hecho, en la plenitud de las políticas neoliberales chilenas de mediados de los`80, el Gobierno Militar sostuvo que "la planificación del desarrollo urbano es una función privativa del Estado” (DS No 31, de 5 de marzo de 1985, que establece la nueva Política Nacional de Desarrollo Urbano). Por su parte, el artículo 66 LGUC no deja lugar a duda sobre lo afirmado, al disponer que "la formación de nuevas poblaciones, barrios, grupos o conjuntos habitacionales deberá respetar las disposiciones de esta ley y su Ordenanza General, y del Plan Regulador y Ordenanza Local, en cuanto al uso del suelo, trazados viales, densidades, superficie mínima predial, coeficientes de constructibilidad y demás disposiciones de carácter urbanístico". 


\section{B) La atribución de potestades urbanísticas}

Las potestades en materia urbanísticas también les son entregadas ley, desde la atribución para fijar las políticas, planes y programas del sector (Ministerio de Vivienda y Urbanísmo); ejercer en la potestad de planificación e intervenir en su procedimiento (SEREMIS de Vivienda y Urbanísmo, Municipalidades y Gobiernos Regionales); así como las potestades concretas de autorización, fiscalización y sanción (Municipalidades y sus respectivas Direcciones de Obras). Todo lo anterior no es sino colorario del principio de legalidad en su dimensión dinámica, esto es, como conjunto de potestades de actuación u obrar, tal como lo consagran la Constitución y la Ley No 18.575 .

\section{C) La autotutela administrativa en materia urbanística}

La autotutela administrativa es un privilegio que se reconoce a los órganos de la Administración frente al ordenamiento jurídico y a los Tribunales de Justicia, para crear, modificar o extinguir situaciones jurídicas de terceros, aun en contra de su voluntad y, en su caso, para ejecutar materialmente sus propias decisiones. Por tal razón se distingue entre autotutela declarativa y la autotutela ejecutiva ${ }^{62}$.

Sin embargo, este principio tan asentado en nuestra doctrina y jurisprudencia ha sido objeto de serios cuestionamientos en Chile ${ }^{63}$. En efecto, el problema central que plantea el principio de autotutela administrativa es su compatibilidad frente a un sistema constitucional que se construye sobre el principio de la heterotutela o heterocomposición, entregando al Estado, a través de los tribunales de justicia, el ejercicio del poder jurisdiccional: conocer las causas civiles y criminales, resolverlas y hacer ejecutar lo juzgado (artículo 76 Constitución). A este respecto, se

62 En expresión de Eduardo García de Enterría, el sometimiento general de los sujetos de Derecho al principio de "paz jurídica" implica la carga de postular la tutela judicial de los derechos, tanto en el aspectos declarativo de estos como en el ejecutivo, o imposición de hecho frente a las resistencias privadas, siendo el fenómeno de autotutela algo excepcional en las relaciones privadas, además de ser facultativa y no obligatoria. En cambio, la autotutela de la Administración es, en primer término, general y luego define un ámbito necesario de actuación que el juez no puede interferir salvo en un momento muy concreto de su desarrollo. El mismo autor ha destacado la forma como la autotutela se ha configurado históricamente producto de un largo proceso y que la hace identificable como un principio general del ordenamiento jurídico. Así, la Administración puede tutelar por sí misma sus propias situaciones jurídicas, incluso sus pretensiones innovativas del statu quo, eximiéndose de la necesidad, común a los demás sujetos, de recabar la tutela judicial. Véase García de Enterría, Eduardo y Fernández, Tomás-Ramón (2001) Curso de Derecho Administrativo. T. I, 10 ed. Madrid: Civitas, pp. 505-508.

63 Sото KLoss, Eduardo (2009) Derecho Administrativo, Temas Fundamentales, Santiago: LegalPublishing, pp. 390-391 y pp. 414-417. 
ha de reconocer que la denominación utilizada (autotutela administrativa) si bien tiene la virtud de explicar de forma gráfica las formas de actuación de estas entidades en ejercicio del poder público, lleva al equívoco de entender que estos órganos ejercen justicia por su propia mano, es decir, una actividad de naturaleza jurisdiccional que está entregada a los tribunales de justicia. Este es quizás el principal reparo a la denominación utilizada para describir este fenómeno y, a la vez, el principal argumento para cuestionar su constitucionalidad.

En nuestra opinión el privilegio de la autotutela no se puede asimilar al ejercicio de una función jurisdiccional. Cuando un órgano administrativo conoce de un asunto de su competencia, interpreta las normas y adopta una determinación, sigue las etapas propias que demanda el razonamiento jurídico y la labor que corresponde a todo operador del Derecho. En este proceso necesariamente la determinación del sentido objetivo de las normas constituye un proceso intelectual necesario e ineludible, que no es sino la interpretación de dichas normas. Esto se traduce, a su vez, en las actuaciones formales propias de la Administración, como es el procedimiento y el acto administrativo. En este punto, la voluntad de la Administración se expresa en estos actos, que bajo ningún respecto pueden identificarse con actuaciones de naturaleza jurisdiccional, no solo desde el punto de vista formal, sino también material. En efecto, los actos administrativos no tienen la fuerza obligatoria ni el efecto propio de una resolución judicial, como es resolver la cuestión con fuerza de cosa juzgada. Además, se trata de actos plenamente revisables por los tribunales de justica, quienes tendrán la última palabra para decidir sobre la validez o no de dichas actuaciones, sin ulterior recurso. Además, en este plano, la autotutela administrativa no puede ser considerada una actividad jurisdiccional pues, como bien señala Feliciano Benvenuti, la tutela jurisdiccional es siempre, por definición, imparcial, neutra o de tercero, mientras que la actuación de la Administración es siempre parcial ${ }^{64}$.

Tal como hemos tenido ocasión de explicar, la posición que tiene el Estado frente al ser humano (servicialidad), el deber de promoción del bien común y de integración armónica de todos los sectores de la Nación que le impone la Carta fundamental (artículo $1^{\circ}$ ), exigen que este deba adoptar todas las medidas y ejercer las atribuciones que el ordenamiento jurídico le confiere destinadas a cumplir un rol de conformación social que responda a estos valores y bienes constitucionales. Estas exigencias han llegado a un crecimiento exponencial frente a una sociedad que se ha hecho más compleja desde la revolución industrial, llegando a lo que se ha denominado la moderna sociedad del riesgo. Todo lo anterior ha

64 Benvenuti, Feliciano (1959), VOZ “Autotutela (diritto amministrativo)", en Enciclopedia del Diritto, Milán, Giuffré. 
demandado una intervención decidida del Estado mediante una acción oportuna y eficaz, la que muchas veces no se encuentra en la naturaleza, dinámica y ritualidad propia de los procesos judiciales y que exige, por lo tanto, asumir tal función a través de sus órganos administrativos, dejando para una segunda fase el control jurisdiccional ${ }^{65}$.

Esto son los elementos y factores que determinan también la existencia de estos poderes en el ámbito del Derecho urbanístico: la urgencia de enfrentar de forma eficiente, eficaz y oportuna un crecimiento urbano cada vez más creciente, la necesidad de ordenar racionalmente las actividades que se realicen sobre el suelo y la imposibilidad de que la sociedad de forma espontánea tenga capacidad de enfrentar estos problemas sin la necesidad de la intervención de los órganos públicos.

En el caso de nuestro ordenamiento, la autotuela se expresa en diversas potestades públicas, como las siguientes:

- En la función de fiscalización de las obras de edificación y de urbanización, que corresponde a las Direcciones de Obras Municipales, permitiéndoseles el libre acceso a todas estas obras, exigiéndose la recepción formal de las mismas para fiscalizar las normas sobre seguridad y conservación de las edificaciones (artículo 142 y 144 LGUC);

- El Director de Obras Municipales puede ordenar, mediante resolución fundada, la paralización de cualquier obra en los casos en que hubiere lugar a ello (artículo 146 LGUC). Lo anterior no obsta que frente al incumplimiento de lo anterior, el Director de Obras pueda solicitar a la autoridad judicial la clausura de las obras (artículo 147 LGUC);

- La misma autoridad puede ordenar la terminación de las obras de edificación de un inmueble, que hubieren sido paralizadas, siempre que por su falta de terminación presentaren mal aspecto, o implicaren riesgo de daño a terceros (artículo 158 LGUC), y

- También se le entrega al Alcalde, a petición del Director de Obras, la facultad de ordenar la demolición total o parcial de las obras, a costa del propietarios que no cumplen con las normas urbanísticas o en caso de peligro de derrumbe inminente de las mismas (artículos 148 y 156 LGUC). La misma facultad se reconoce al Secretario Regional de Vivienda y Urbanismo respecto de las obras que se ejecuten en contravención a los planes reguladores o sin haber obtenido el correspondiente permiso municipal, con el solo informe del Director de Obras Municipales respectivo (artículo 157 LGUC).

65 Cordero, Eduardo y Aldunate, Eduardo (2012), "Las bases constitucionales de la potestad sancionadora de la Administración", en Revista de Derecho, Pontificia Universidad Católica de Valparaíso, № 39, pp. 354-355. 
No obstante lo anterior, la aplicación de las sanciones por infracción a la normativa urbanística se encuentra judicializada, y se entrega al conocimiento de los Jueces de Policía Local (artículo 21 LGUC), lo cual no le resta importancia a la existencia de poderes de autotutela de la Administración urbanística en temas que resultan centrales respecto del cumplimiento de la legalidad urbanística.

\section{D) El bloque de legalidad y los instrumentos de planificación}

Como bien señala Luciano Parejo Alfonso, en algunos sectores de la realidad que, por razón de sus características, precisan de una regulación administrativizada, resulta impracticable una programación adecuada y suficiente de la acción de la Administración, por imposibilidad para el legislador de prever y tratar anticipadamente todos los supuestos posibles en la práctica, especialmente por la naturaleza compleja y evolutiva de la materia o la importancia en ella de la ciencia y la técnica ${ }^{66}$. Por tal razón, se debe incrementar el tracto del proceso en la toma de decisiones públicas más allá de la Ley y el Reglamento, con el objeto de incrementar la previsibilidad de la acción administrativa y, por tanto, de la seguridad jurídica. Es así como aparecen instrumentos como la planificación y las bases, las cuales fijan el marco normativo que ha de regir un determinado proceso de toma de decisiones. Esta es la situación que se presenta en el Derecho urbanístico, donde vemos una pluralidad de fuentes que parten desde la Ley, siguen con una frondosa regulación reglamentaria y continúa con un conjunto de instrumentos de planificación territorial de clara naturaleza normativa, con lo cual se amplía el abanico de lo que conforma el bloque de legalidad.

Ahora bien, en el plano legislativo rige la Ley General de Urbanismo y Construcciones (LGUC), sancionada a través del Decreto con Fuerza de Ley No 458 de 1975, y que ha sido objeto de más de una veintena de modificaciones. Si bien estamos ante un cuerpo legal que regula materias que no pueden ser objeto de delegación legislativa ${ }^{67}$, esta es una norma preconstitucional, por lo que no quedó sujeta a las limitaciones que impuso la CPR de 1980 en estas materias. No obstante, las modificaciones posteriores que se han hecho a dicho cuerpo legal, solo se pueden tener lugar a través de leyes formales.

Esta ley tiene por objeto la regulación de la "planificación urbana", la "urbanización" y la "construcción"68, y establece las fuentes del Derecho urbanístico en nuestro país (o niveles de acción ${ }^{69}$, como los denomina):

Parejo Alfonso, Luciano (2003) Derecho administrativo. Barcelona: Ariel, pp. 655-656.

Artículo 61.2 CPR.

Artículo 1० LGUC.

Artículo 2o LGUC 
a) La Ley General, que contiene los principios, atribuciones, potestades, facultades, responsabilidades, derechos, sanciones y demás normas que rigen a los organismos, funcionarios, profesionales y particulares, en las acciones de planificación urbana, urbanización y construcción.

b) La Ordenanza General, que contiene las disposiciones reglamentarias de esta ley y que regula el procedimiento administrativo, el proceso de planificación urbana, urbanización y construcción, y los estándares técnicos de diseño y construcción exigibles en los dos últimos. El Decreto Supremo No 47, de 19 de mayo de 1992 fija el nuevo texto de la Ordenanza General de la Ley General de Urbanismo y Construcciones, la que ha sufrido importantes modificaciones, dentro de las cuales destacan las introducidas por el Decreto Supremo No 70, de 25 de junio de 2001.

c) Las Normas Técnicas, que contienen y definen las características técnicas de los proyectos, materiales y sistemas de construcción y urbanización, para el cumplimiento de los estándares exigidos en la Ordenanza General.

A este conjunto de fuentes se deben agregar las instrucciones que debe dictar el Ministerio de Vivienda y Urbanismo, a través de la División de Desarrollo Urbano, para la aplicación de las disposiciones de la LGUC y de la OGUC, lo que se hace mediante circulares ${ }^{70}$.

Sin lugar a dudas, las normas más relevantes en materia urbanística están constituidas por los instrumentos de planificación territorial que son fruto de la planificación urbana. La LGUC define en su artículo 27 a la planificación urbana como el proceso que se efectúa para orientar y regular el desarrollo de los centros urbanos en función de una política nacional, regional, comunal de desarrollo socioeconómico. Ahora bien, no existe en Chile un único instrumento de planificación urbanísticas, sino que hay múltiples instrumentos que cumplen tal objetivo.

Tal como se ha dicho, la LGUC contempla un sistema de planificación urbana a nivel nacional, sin embargo nunca se ha aprobado un instrumento de esta naturaleza. En definitiva, en Chile son "Instrumentos de Planificación Territorial" los indicados in supra: El Plan Regional de Desarrollo Urbano, el Plan Regulador Intercomunal o Metropolitano, el Plan Regulador Comunal, el Plan Seccional y el Límite Urbano.

70 Artículo 4 LGUC. Originalmente la LGUC establecía que esta función correspondía a las Secretarías Regionales Ministeriales, que son órganos desconcentrados territorialmente del MINVU en las 13 regiones de Chile. La inseguridad que daba la disparidad de criterios en estas materias y la necesidad de precisar las facultades que ya ejercía en esta materia la DDU, en virtud de lo dispuesto en el artículo 12, letra h) del DL No 1.305 , de 19 de febrero de 1976, fueron el origen de la modificación introducida por la Ley 19.472, de 16 de septiembre de 1996 a esta disposición. Estas circulares se encuentran publicadas actualmente en internet en la siguiente página web: http://www.minvu.cl. 
De esta forma, la legalidad urbanística está conformada por un conjunto de normas de naturaleza legal, reglamentaria y diversos instrumentos de planificación urbanística, considerando que la naturaleza de las materias que se regulan exigen un abanico más amplio de normas, aunque todas se encuentran engarzadas en un tracto de decisiones públicas que parten con una ley que establece los principios y normas básicas, luego se complementan con una normativa reglamentaria que detalla y precisa el contenido legal, para terminar con los instrumentos de planificación, que precisan en cada ámbito una determinada política sobre el territorio atendiendo a las diversas circunstancias que estas plantean desde la perspectiva geográfica, social, económica y cultural.

\section{E) La determinación del régimen objetivo de la propiedad, reserva legal y contenido esencial}

Las normas urbanísticas (legislación, reglamentos e instrumentos de planificación territorial), configuran objetivamente el régimen jurídico del suelo, conforme al cual los propietarios van a incorporar a su esfera patrimonial derechos y facultades urbanísticas. Mediante este proceso se produce la subjetivización o patrimonialización de dichos derechos y facultades, sujeto a las condiciones, cargas, obligaciones o deberes que imponga dicha normativa.

En la determinación de este régimen objetivo le compete una función capital al legislador, a quien corresponde establecer la regulación básica que contenga el contenido material de la propiedad inmueble, condicionando las normas administrativas inferiores que deben complementarlo, según los términos establecidos en los Nos. 24 y 26 del artículo 19 de la Constitución. Así, en esta labor, el legislador debe cumplir las siguientes tareas:

a) Debe garantizar que el derecho objetivo de propiedad que resulta de dicho régimen jurídico responda como mínimo al contenido esencial que se reconoce a dicho derecho propiedad, sin desfigurarlo o desnaturalizarlo;

b) Se ha de cumplir con el principio de reserva legal, estableciendo el contenido básico del derecho de propiedad, sin perjuicio de que su regulación sea complementada por normas administrativas posteriores, $y$

c) Debe determinar los diversos estatutos de la propiedad, sobre la base de la distinta función social que se asigna al suelo, como se analizará a continuación.

En efecto, nuestra Constitución establece que las limitaciones a la propiedad que emanan de la función social y el derecho a desarrollar actividades económicas son materias cuya regulación básica es de reserva legal 
(artículo 19 Nos. 21, 24 y 26, y artículo 60 No 20). A su vez, en dicha regulación se debe respetar el contenido esencial de dicho instituto (artículo 19 No 26), sin perjuicio de que se pueda establecer, a partir de un contenido mínimo, diversos estatutos de la propiedad del suelo en atención a la distinta función social que se asigna al mismo. En este plano, el legislador cumple una función de regulación y de delimitación del estatuto de la propiedad, conforme al cual los particulares pueden patrimonializar diversas facultades contenidas en dicho Derecho objetivo. A su vez, si bien en esta función el legislador goza de un amplio margen de discrecionalidad, esto no significa que pueda desfigurar ni deformar la esencia objetiva del derecho de propiedad, como la forma más intensa de titularidad sobre una cosa.

\subsection{3) La función social de la propiedad y la pluralidad de estatutos}

Nuestra Carta Fundamental garantiza el derecho de propiedad en sus diversas especies sobre toda clase de bienes corporales e incorporales. Además, reconoce -como lo ha dicho el Tribunal Constitucional-, la existencia de funciones o finalidades no individualistas que restringen una consideración puramente absolutista de la propiedad y de los derechos del propietario sobre la misma ${ }^{71}$. Estas finalidades no individualistas se distinguirían bajo dos categorías diferenciadas en incisos distintos: unas derivan de la función social y dan lugar a limitaciones, mientras que las otras serían por razones de utilidad pública e interés nacional, dando lugar a las privaciones ${ }^{72}$.

Ahora bien, la articulación de los conceptos de función social, limitaciones y privaciones al domino tienen una particular importancia en el ámbito de la regulación urbana. En efecto, tal como hemos visto in supra, al momento de enfrentar la regulación en el uso del suelo, primero el legislador y luego las autoridades administrativas, configuran diversos regímenes o estatutos de la propiedad del suelo en razón de su función social (limitaciones), estableciendo derechos, obligaciones y cargas. A su vez, la

71 Sentencia Rol No 2299/2012, considerando $8^{\circ}$.

72 En efecto, dicha Magistratura ha señalado que el inciso segundo del No 24 del artículo 19 de la Constitución Política configura las limitaciones y obligaciones fundadas en la función social de la propiedad cuyas causales han sido señaladas específicamente por el legislador, a saber, los intereses generales de la Nación, la seguridad nacional, la utilidad y salubridad públicas y la conservación del patrimonio ambiental. En concepto de dicho Tribunal, "la función social de la propiedad significa que ésta tiene un valor individual y social por lo que debe estar al servicio de la persona y de la sociedad. El dominio además de conferir derechos, impone deberes y responsabilidades a su titular. Estos deberes y responsabilidades que buscan armonizar los intereses del dueño con los de la sociedad, constituyen la función social de la propiedad." Asimismo ha precisado que "las limitaciones suponen el establecimiento de determinadas cargas al ejercicio de un derecho, dejándolo subsistente en sus facultades esenciales." (Sentencias Roles Nos 245-246, considerandos $22^{\circ}$ y $25^{\circ}$ ). 
ejecución de dichas determinaciones previstas en los instrumentos de planificación se pueden expresar en meras limitaciones (normas sobre alturas, regulación de las fachadas y techumbres, etc.) en razón de la función social que deben cumplir, y que no dan derecho a indemnización alguna. Sin embargo, en muchos casos la ejecución de estos instrumentos puede significar la existencia de privaciones respecto de derechos ya adquiridos, como sería bajar las alturas de edificios ya construidos, prohibir un determinado uso del suelo respecto de establecimientos que operan en el sector, transformar inmuebles de propiedad privada en bienes nacionales de uso público (calles, avenidas, plazas, parques, etc.). En todos estos casos nos encontramos frente a privaciones del dominio que exigen el pago de una indemnización, salvo que se adopte la decisión de respetar dichos derechos mientras aquello no sea posible llevar adelante la expropiación.

Como lo ha reconocido la doctrina y la jurisprudencia comparada, la propiedad del suelo, como toda forma de propiedad, está sujeta a una función social que debe cumplir, lo que implica no solo limitaciones a su contenido -lo que nadie discute-, sino también las redefiniciones o delimitaciones, que se traducen, en definitiva, en la configuración del mismo. Esta configuración de la propiedad atendiendo a la función social que se le asigna afecta ante todo al ius aedificandi, entendida esta facultad en sentido amplio, abarcando el derecho a urbanizar y edificar sobre el suelo. Así, la función social es el elemento primordial en la configuración del régimen de la propiedad, no solo por su expresa previsión constitucional, sino también por la exigencia que tiene el Estado en orden a garantizar el bien común.

En la medida que la ordenación urbanística a través de los planes de ordenación urbana configuran y cierran el régimen jurídico de la propiedad del suelo, el legislador se está moviendo en el plano objetivo, configurando el estatuto de la propiedad de forma abstracta, determinando el contenido material del derecho, así como las facultades y obligaciones que esta llevará incita. Esta facultad para configurar el régimen de la propiedad ha sido reconocida a partir del concepto de función social, como elemento estructurante del concepto de propiedad.

En este sentido, la legislación urbanística no se ha limitado a establecer un estatuto de la propiedad de carácter unitario, sino que ha procedido a su diversificación en atención a los diversos fines que se asigna a cada uno de los espacios del territorio. El instrumento que ha utilizado para tal efecto es la técnica de la "clasificación" en cuya virtud se establece a nivel legislativo el régimen jurídico de cada clase de suelo en abstracto, para ser vinculado después con cada una de las porciones del territorio a través de la planificación urbana.

Tal como lo hemos señalado, la clasificación tradicional del suelo en Chile distingue entre "área urbana" y "área rural". A su vez, la primera de ellas distingue entre "suelo urbano consolidado" y "suelo urbanizable". 
Para comprender esta distinción en la doctrina comparada se recurrió tempranamente a la teoría de origen italiano de la pluralidad de propie$\operatorname{dad}^{73}$, como categoría de análisis para comprender los diversos regímenes que surgen de la ordenación urbanística del suelo ${ }^{74}$.

\subsection{4) El reconocimiento y protección de los derechos adquiridos conforme a los instrumentos de planificación territorial}

Bien puede ocurrir que la vigencia efectiva de los instrumentos de ordenación territorial no solo signifiquen limitaciones a la propiedad, sino que también conlleven privaciones producto de la afectación de derechos ya adquiridos bajo una anterior regulación. En este caso, la distinción entre una propiedad en sentido objetivo (régimen jurídico) y subjetivo (derecho) nos permite comprender de mejor forma la articulación y relaciones derivadas de estas modificaciones. En efecto, todo cambio o modificación del régimen jurídico de la propiedad del suelo se debe entender legítima en cuanto se lleva a cabo en un plano general o abstracto, debiendo respetar en todo caso el contenido mínimo o esencial. Por tal razón, en esta función de limitación no surge el derecho a ser indemnizado. Sin embargo, en el evento de que en el caso concreto la aplicación de las nuevas normas signifiquen una privación patrimonial, se deben adoptar las medidas para resguardar dichos derechos. En este caso existen dos posibilidades: establecer un régimen transitorio que respete tales derechos o, simplemente, hacer efectiva la privación y que se indemnice el daño patrimonial efectivamente causado.

73 De Los Mozos, José Luis (1961) “El urbanismo desde la perspectiva del Derecho privado". Revista de Derecho Privado, T. XLV, enero-diciembre, p. 294 y pp. 296 y ss.

74 Sobre la materia se puede consultar Condero Eduardo (2008b) "De la propiedad a las propiedades: La evolución de la concepción liberal de la propiedad”, en Revista de Derecho de la Pontificia Universidad Católica de Valparaíso, No 31, pp. 493-525. El Tribunal Constitucional español ha declarado la compatibilidad de esta construcción dogmática con la actual Constitución española, dando cuenta de la estrecha vinculación entre la concepción institucional o dimensión objetiva de la propiedad y la existencia de pluralidad de propiedades: "[...] la propiedad privada, en su doble dimensión como institución y como derecho individual, ha experimentado en nuestro siglo una transformación tan profunda que impide concebirla hoy como una figura jurídica reconducible exclusivamente al tipo abstracto descrito en el art. 348 CC[...] Por el contrario, la progresiva incorporación de finalidades sociales relacionadas con el uso o aprovechamiento de los distintos tipos de bienes sobre los que el derecho de propiedad puede recaer ha producido una diversificación de la institución dominical en una pluralidad de figuras o situaciones jurídicas reguladas con un significado y alcance diversos. De ahí que se venga reconociendo con general aceptación doctrinal y jurisprudencial la flexibilidad o plasticidad actual del dominio que se manifiesta en la existencia de diferentes tipos de propiedades dotadas de estatutos jurídicos diversos, de acuerdo con la naturaleza de los bienes sobre los que cada derecho de propiedad recae”. FJ. 2. ${ }^{\circ}$, Sentencia Rol No 37/1987, de 26 de marzo. 
Esta es la solución que se adopta en los sistemas comparados y que en Chile conocemos como "congelamiento". En este sentido, el artículo 62 LGUC dispone que "los terrenos cuyo uso no se conformare con el Plan Regulador se entenderán congelados, en el sentido de que no podrá aumentarse el volumen de construcción en ellos existentes, rehacer las instalaciones, ni otorgarse patente a nuevo propietario o arrendatarios". De esta forma, los propietarios pueden incorporar a su patrimonio el derecho a edificar y los usos atribuidos por los instrumentos de planificación mientras estos se encuentren vigentes, y en la medida que cumplan con las cargas y obligaciones que les impone la normativa urbanística. Una vez que se modifique esta regulación y no se hayan cumplido con las condiciones previstas en la misma, la edificabilidad y los usos pretéritos se pierden indefectiblemente.

Esta "patrimonialización" del uso y la edificabilidad contenido en los planes reguladores se produce normalmente con el otorgamiento del permiso de urbanización o edificación, y llega a comprender incluso a la aprobación de anteproyectos (artículo 116 LGUC). Así, los permisos otorgados y no materializados durante la vigencia de un determinado plan regulador tienen vigencia ultractiva respecto de las futuras normas urbanística. En estos casos, la única posibilidad de ejecutar el nuevo plan frente a los permisos ya otorgados es la expropiación ${ }^{75}$.

Sin embargo, no existe en nuestra jurisprudencia un criterio claro para establecer los casos en que las medidas adoptadas por la autoridad podrían constituir privaciones que dan derecho a indemnización o simples limitaciones al dominio, como ha sucedido con la Ley No 17.288, sobre Monumentos Nacionales ${ }^{76}$.

Cordero (2008a) 106 y 107.

El caso más paradigmático respecto de la falta de un criterio generalmente aceptado sobre la materia se encuentra en el la Sentencia del Tribunal Constitucional, recaída en el caso denominado "Inmobiliaria Santa Beatriz", STC Rol No 2299/12, de 29 de marzo de 2014, en la cual se rechazó un recurso de inaplicabilidad en relación con los artículos 29 y 30 de la Ley No 17.288 , por igualdad de votos ( 5 a favor de acoger el recurso y 5 por rechazarlo). La discusión central era si se trataba de una privación que daba derecho a indemnización o una limitación que emanaba de la función social. En un caso anterior, conocido como "Sociedad Inmobiliaria Maullín Ltda.” la Corte Suprema acogió un recurso de inaplicabilidad en contra de la misma ley (SCS Rol No 4309/2002, de 18 de agosto de 2004), aunque en un pronunciamiento posterior declaró que no era procedente el derecho a indemnización por los perjuicios que ocasionaban tales medidas ("Sociedad Inmobiliaria Maullín Ltda. con Fisco de Chile", SCS Rol Rol No 552-2008, de 5 de octubre de 2010). Sobre la materia se puede consultar Matute E., Carlos (2014) Expropiaciones Regulatorias, Santiago: Thomson Reuters; Aldunate Lizana, Eduardo (2006) "Limitación y expropiación: Scilla y Caribdis de la dogmática constitucional de la propiedad”. Revista Chilena de Derecho, vol. 33, № 2, y Doménech Pascual, Gabriel (2012). "Cómo distinguir entre una expropiación y una delimitación de la propiedad no indemnizable". Revista para el Análisis del Derecho, 1/2012. 


\subsection{5) Los problemas del principio de igualdad y la justa distribución de beneficios y cargas}

La igualdad constituye en nuestro ordenamiento no solo un valor constitucional (artículo 10), sino también un derecho garantizado constitucionalmente. En tal sentido, toda política pública, incluyendo entre estas a las políticas sobre el territorio y el urbanismo, implementada por la autoridad pública, debe respetar y promover este valor y principio. Sin embargo, la acción urbanística en sus previsiones tiende a la diversificación del régimen del suelo, creando distintos estatutos propietarios conforme a la función social que se le asigna y, por lo tanto, distintas formas de patrimonializar el uso y la edificabilidad. De esta forma, no resulta muchas veces equitativo ni justo los derechos y cargas que atribuye el plan a los propietarios, al punto que en muchos casos puede llegar a otorgar un contenido mínimo de edificabilidad (artículos 55 y 59 LGUC) ${ }^{77}$.

Los planes de ordenación urbana son fuente de enormes plusvalías, pero no consideran en una dimensión estática una distribución equitativa de las mismas. Para este efecto resulta necesario que existan mecanismos de gestión urbanística que permitan distribuir de forma equitativa los beneficios y cargas que nacen del plan. Sin embargo -y como lo hemos señalado-, en Chile no existe una regulación en tal sentido. Los propietarios ejecutan el plan a su voluntad y conforme a los derechos y cargas que se le imponen de forma individual. No existe la obligación ni el deber de realizar actuaciones conjuntas, que permita equidistribuir los beneficios y cargas de la acción urbanística. Por lo tanto, no existe ni se garantiza la igualdad de los propietarios frente a los planes de ordenación, que son expresión de una política urbana.

77 El artículo 59 LGUC es la norma que ha planteado de forma patente los problemas que existen en nuestro ordenamiento ante la ausencia de sistemas integrados de ejecución del planteamiento. Esta disposición declara de utilidad pública $-\mathrm{y}$ por tanto, sujeto a expropiación- determinados bienes nacionales de uso público previstos en los planes reguladores. Sin embargo, ante la carencia de recursos públicos para proceder a su expropiación, los propietarios quedaban privados de los usos urbanísticos de sus inmuebles. Por tal razón, se dictó la Ley No 19.939, de 13 de febrero de 2004, que declara la caducidad de dichas declaratorias y permitía incorporar al uso urbano los terrenos afectados, previa dictación de las normas respectivas conforme a los usos de la zona predominante de las adyacentes al terreno. En este caso, se entendía que el hecho de no expropiar durante cierto tiempo constituía una carga que no debían soportar los propietarios y esto exigía aplicar una sanción radical: la caducidad de la declaratoria de utilidad pública en plazos de 10 o 5 años, dependiendo de la afectación. Si bien la norma permitió renovar por una vez esta declaración, indefectiblemente se produjo el efecto contrario, ya que lentamente comenzaron a desaparecer de los planes reguladores los parques intercomunales, comunales, vías troncales, etc., todos los elementos necesarios para hacer ciudad y contar con una ordenación racional del suelo. Esto llevó a cambiar nuevamente la norma a través de la Ley No 20.791, de 29 de octubre de 2014, con la cual se vuelve a la regla anterior, aunque se reconoce un mínimo de edificabilidad. 
Esta es quizás una de las grandes carencias de nuestro sistema urbanístico, el cual reclama con urgencia una revisión para hacer efectivo el mandato constitucional en orden a garantizar no solo una igualdad formal, sino también sustantiva ${ }^{78}$.

\section{CONCLUSIONES}

El Derecho urbanístico es una disciplina que tiene su origen en una mayor intervención del Estado en la sociedad a partir de los problemas sanitarios, de higiene y de seguridad que se comienzan a experimentar en las últimas décadas del siglo XX. Si bien en un comienzo fue considerado como una legislación excepcional y contingente que solo establecía limitaciones externas al derecho de propiedad, su persistencia y el avenimiento del Estado social hacen que se consolide bajo un sistema integrado de técnicas de intervención que darán forma a una disciplina jurídica.

En el caso de Chile, este fenómeno comenzará a experimentarse a partir de 1874 con una legislación urbanística inicial, hasta conformar un sistema integrado con la primera Ley General de Urbanismo y Construcción de 1931. A partir de ese período, se comienza a delinear el contenido, los principios y las instituciones del Derecho urbanístico que permiten sostener su autonomía. Así, se consolida la planificación urbana como una técnica de ordenación del espacio, se establecen distintos tipos de suelo mediante la figura del límite urbano (área urbana y rural), se establecen las formas de zonificación del suelo, los derechos y deberes de los propietarios que configuran al mismo tiempo el régimen urbanístico de la propiedad. No obstante que la gestión urbanística no es sistemática y queda entregada fundamentalmente a los particulares, se establece todo un sistema de control preventivo y represivo de la legalidad urbanística, donde la principal figura es el permiso de edificación.

Si bien el Derecho urbanístico forma parte del Derecho público y se integra dentro del Derecho administrativo especial, la manera como se traban cada una de las técnicas de intervención (planificación, permisos de edificación, inspección y control, etc.), permite sostener la existencia de una disciplina que cuenta con principios propios, partiendo por reconocer que el urbanismo constituye una función pública, pues las determinaciones sobre la forma de crear y proyectar la ciudad están des-

78 Este tema está asociado al problema de la captura de las plusvalías y que en Chile se encuentran todavía en discusión. Un cuerpo legal de interés en esta materia lo constituye la Ley No 19.865 , de 1 de abril de 2003, sobre financiamiento urbano compartido, el que tiene por objeto la construcción de infraestructura urbana por la vía de las concesiones. Sin embargo, no deja de ser un mecanismo asistemático que no considera a las plusvalías que resultan del proceso urbano como un instrumento de financiamiento. 
vinculadas de las facultades del dominio. Además, supone el respecto de la legalidad urbanística que se conforman fundamentalmente por los instrumentos de planificación territorial y el respeto y garantía del derecho de propiedad, aunque debe resolver los serios problemas de desigualdad que genera la distribución de beneficios y cargos que derivan de la planificación urbana.

Conforme a lo expuesto, el Derecho urbanístico chileno constituye una rama del Derecho cuyos contenidos, instituciones y principios conforman un sistema que, desplegándose en el ámbito del Derecho público y estrechamente vinculado al Derecho administrativo, permiten sostener su autonomía disciplinar y justificar un análisis dogmático a partir de elementos que le son propios y singulares.

\section{BibLIOGRAFÍA}

- AAVV (1999) Seminario Internacional "A 20 Años de la Liberalización de los Mercados de Suelo Urbano en Chile". 7 y 8 de octubre, 1999. Santiago: Cámara de Diputados de Chile.

- Aldunate Lizana, Eduardo (2006) "Limitación y expropiación: Scilla y Caribdis de la dogmática constitucional de la propiedad". Revista Chilena de Derecho, vol. 33, No 2.

- Álvarez Cruz, Raúl (1988) "La disciplina urbanística. Su entidad ante el Derecho". Revista de Ciencias Sociales Derecho y Sociedad, No 2, primavera.

- Baudry-Lacantinerie, Gabriel (1908) Précis de Droit civil. vol. 1, $10^{a}$ ed. Paris: Larose.

- Baudry-Lacantinerie, Gabriel y Cheveau, M. (1905) Traité théorique et pratique de droit civil: Des Biens. $3^{\text {a }}$ ed. Paris: Recueil Sirey.

- Brahm García, Enrique (1999) Propiedad sin Libertad. Chile 19251973. Santiago: Universidad de los Andes.

- Carceller Fernández, Antonio (1989) Instituciones de Derecho urbanistico. Madrid: Montecorvo.

- Cardeller Fernández, Antonio (1992). Introducción al Derecho urbanístico. Madrid, Tecnos, p. 17.

- Cea Egaña, José Luis (1988) Tratado de la Constitución de 1980. Santiago: Jurídica de Chile.

- Colina Garea, Rafael (1997) La función social de la propiedad privada en la Constitución Española de 1978. Zaragoza: Bosch.

- Cordero, Eduardo (2008a). "El derecho urbanístico chileno y la garantía constitucional de la propiedad", Nomos, No 2 . 
- Cordero, Eduardo (2008b). "De la propiedad a las propiedades: La evolución de la concepción liberal de la propiedad", en Revista de Derecho de la Pontificia Universidad Católica de Valparaiso, No 31.

- Cordero, Eduardo y Aldunate, Eduardo (2012). "Las bases constitucionales de la potestad sancionadora de la Administración", en Revista de Derecho, Pontificia Universidad Católica de Valparaiso, No 39.

- De los Mozos, José Luis (1961). "El urbanismo desde la perspectiva del Derecho privado". Revista de Derecho Privado, XLV, enerodiciembre.

- De Vita, Anna (1969) La propietà nell'esperienza giuridica contemporánea: analisi comparativa del diritto francese. Milano: Giuffrè.

- Doménech Pascual, Gabriel (2012). "Cómo distinguir entre una expropiación y una delimitación de la propiedad no indemnizable". Revista para el Análisis del Derecho, 1/2012.

- Fernández, Tomás-Ramón (1997) Manual de Derecho Urbanistico. 12a ed. Madrid: El Consultor.

- Fernández Richard, José y Holmes Salvo, Felipe (2008) Derecho Urbanistico Chileno. Santiago: Editorial Jurídica de Chile.

- Figueroa Velasco, Patricio y Figueroa Valdés, Juan Eduardo (2006). Urbanismo y Construcción. Santiago, LexisNexis, pp. 5-7.

- Fueyo Laneri, Fernando (1967). "El problema de las autonomías o especialidades". Revista de Derecho Público, No 17.

- García de Enterría, Eduardo y Fernández, Tomás-Ramón (2001) Curso de Derecho Administrativo. T. I, 10 ed. Madrid: Civitas.

- García de Enterría, Eduardo y Parejo Alfonso, Luciano (1981) Lecciones de Derecho urbanistico. 2 ed. Madrid: Civitas.

- García-Bellido, Javier (1994). "Inicios del lenguaje de la disciplina urbanística en Europa y difusión internacional de la "Urbanización" de Cerda", en Tiempo y Espacio en el Arte. Homenaje al profesor Antonio Bonet Correa, Tomo II, Madrid, Universidad Complutense de Madrid.

- González Pérez, Jesús (1998) Comentarios a la ley sobre régimen del suelo y valoraciones. Ley 6/1998, de 13 de abril. Madrid: Civitas.

- Guillmore L., Roberto y Guerrero P., Pablo (2001). "Principios del Derecho urbanístico como fuente normativa del desarrollo urbano y las zonas de desarrollo condicionado como instrumento de urbanismo moderno". En Facultad de Derecho de la Universidad del Desarrollo. Derecho urbanistico. Santiago: Universidad del Desarrollo.

- Hattenhauer, Hans (1987) Conceptos fundamentales del Derecho civil. Introducción histórico-dogmática. Traducción de Gonzalo Hernández. Barcelona: Ariel. 
- Holmes Salvo, Felipe (2010) Propiedad Urbana. Régimen Jurídico. Santiago: AbeledoPerrot, pp. 73 y ss.

- Jardí Casany, Enrique (1966) El planeamiento urbanístico. Barcelona: Bosch.

- López y López Ángel (1998). "El derecho de propiedad. Una relectio". Anuario de Derecho Civil, T. LI, fasc. IV, octubrediciembre.

- Marcos Jiménez, Martín (1976) Parcelaciones y reparcelaciones urbanisticas y el registro de la propiedad. Madrid: Montecorvo.

- Martín Blanco, José (1960) Estudios de Derecho Urbanistico. Madrid: Gráficas Expres.

- Martín Blanco, José (1970) Dictámenes y estudios en Derecho urbanístico. Madrid: Montecorvo.

- Martín Gamero, Alberto (1967) Expropiaciones urbanisticas. Madrid: Montecorvo.

- Matute E., Carlos (2014) Expropiaciones Regulatorias, Santiago: Thomson Reuters.

- Ministerio de Vivienda y Urbanismo (1981). "Política Nacional de Desarrollo Urbano, y Conceptos básicos para la formulación de una Política Nacional de Desarrollo Urbano". EURE, vol. II, No 22, septiembre.

- Mohor, Salvador (1989). "Taxonomía de las limitaciones al dominio y derecho de indemnización”. Revista Chilena de Derecho, vol. 16.

- NúNEEz Ruiz, Miguel Ángel (1967). Derecho urbanistico español. Madrid: Montecorvo.

- Nieto, Alejandro (2011). Derecho administrativo sancionador. 4 ed. Madrid: Tecnos.

- Parada, José Ramón (1999). Derecho urbanistico. Madrid, Marcial Pons.

- Parada, José Ramón (1993) Derecho Administrativo. vol. III, 5ª ed. Madrid: Marcial Pons.

- Parejo Alfonso, Luciano (1997) Reivindicación del urbanismo. Liberalización del suelo al servicio del interés general. Madrid: Instituto Pascual Madoz.

- Parejo Alfonso, Luciano (2001) El Estatuto de la propiedad urbana. En AA.VV. Manual de Urbanismo. Madrid: Instituto Nacional de Administración Pública.

- Parejo Alfonso, Luciano (2001). "Algunas consideraciones sobre el derecho de propiedad a la luz de la jurisprudencia constitucional". En López Guerra, Luis (coord.): Estudios de Derecho Constitucional. Homenaje al Profesor Dr. D. Joaquin García Morillo. Valencia: Tirant lo Blanch. 
- Parejo Alfonso, Luciano (2003) Derecho administrativo. Barcelona: Ariel, pp. 655-656.

- Parrochia B. Juan (2001). "Iniciativas sobre Desarrollo Urbano enunciadas por el Ministerio de Vivienda y Urbanismo, marzo de 1979". Revista de Urbanismo, Universidad de Chile, Facultad de Arquitectura, No 4, julio.

- Rajevic Mosler, Enrique (1996). "Limitaciones, reserva legal y contenido esencial de la propiedad privada". Revista Chilena de Derecho, vol. 23, No 1.

- Rajevic Mosler, Enrique (2000). "Derecho y legislación urbanística en Chile". Revista de Derecho Administrativo Económico, vol. II, № 2.

- Rajevic Mosler, Enrique (2001). "La planificación urbana en Chile". Revista de Derecho, Consejo de Defensa del Estado, Año 1, No 3, abril.

- Ríos Álvarez, Lautaro (1985) El urbanismo y los principios fundamentales del Derecho urbanistico. Madrid: Ministerio para las Administraciones Públicas.

- Silva Bascuñán, Alejandro (1999). Tratado de Derecho Constitucional. T. IV, Santiago: Jurídica de Chile.

- Soto Kloss, Eduardo (1996) Derecho Administrativo, T. II. Santiago: Jurídica de Chile.

- Soto Kloss, Eduardo (2009) Derecho Administrativo, Temas Fundamentales, Santiago: LegalPublishing.

- Ugarte Godoy, José Joaquín (2001). "Limitaciones al dominio de las meras restricciones y de cuándo dan lugar a indemnización". Revista Chilena de Derecho, vol. 28, No 2. 